\title{
Grenzen und Grenzräume im Mittelalter: Forschungen, Konzepte und Begriffe
}

\author{
Von
}

\author{
Nikolas Jaspert
}

Möchte man das Generalthema des vorliegenden Sammelbandes, Grenzräume und Grenzüberschreitungen im Mittelalter, dem Betrachter als bildliche Darstellung vor Augen führen, stellt man schnell fest, daß die Zahl einschlägiger Illustrationen beschränkt ist. Denn im Gegensatz zur Moderne gaben im Mittelalter Karten zwar verschiedentlich Herrschaften, seltener aber deren Grenzen wieder - wenn wir vom legendären Reich der eingesperrten und von hohen Mauern umschlossenen Völker Gog und Magog absehen. ${ }^{1}$ Dieses Manko, aber auch die Tatsache, daß im Folgenden nicht allein von politischen Territorialgrenzen gehandelt werden soll, läßt einen auf Darstellungen zurückgreifen, die zwar nicht ausdrücklich eine Grenze wiedergeben sollen, aber verschiedene Elemente beinhalten, die nach Ansicht der neueren Forschung die Grenzen in der vormodernen Epoche kennzeichneten. Eine solche Abbildung liegt mit einem Holzschnitt ${ }^{2}$ aus der Hand des Hans

1 Andrew Runni Anderson, Alexanders Gate, Gog and Magog, and the Inclosed Nations. (Academy publications / The Mediaeval Academy of America, Bd. 5.) Cambridge, Mass. 1932; Dagmar Unverhau (Hrsg.), Geschichtsdeutung auf alten Karten. Archäologie und Geschichte. (Wolfenbütteler Forschungen, Bd. 101.) Wiesbaden 2003; Anna-Dorothee von den Brincken, Fines terrae: die Enden der Erde und der vierte Kontinent auf mittelalterlichen Weltkarten. (Monumenta Germaniae Historica: Schriften, Bd. 36.) Hannover 1992; Evelyn Edson, Mapping Time and Space. How Medieval Mapmakers viewed their world. (The British Library Studies in Map History, Bd. 1.) London 1999; Evelyn Edson / Emilie Savage-Smith / Anna-Dorothee von den Brincken, Der mittelalterliche Kosmos: Karten der christlichen und islamischen Welt. Darmstadt 2005. Carlos Gozalbes Cravioto, La frontera terrestre nazarí en la cartografia medieval, in: II de Estudios de frontera. Actividad y vida en la fontera. En memoria de don Claudio SánchezAlbornoz. Alcalá la Real, 1997. Jaén 1998, 357-370; Gegenbeispiele untersuchen Ana Belén Paniagua Lourtau, Transformaciones geopolíticas en la frontera de Granada a través de su proyección cartográfica (1246-1481), in: Francisco Toro Ceballos / José Rodríguez Molina (Hrsg.), Funciones de la red castral fronteriza. Homenaje a Don Juan Torres Fontes. Congreso celebrado en Alcalá la Real en noviembre de 2003. Jaén 2004, 587-595.

2 Zum Maler Christof Metzger, Hans Schäufelin als Maler. Berlin 2002, mit neuen Erkenntnissen zur Biographie des Künstlers; Peter Strieder, Dokumente und Überlegungen zum Weg Hans 
Leonard Schäufelein vor, eines Alemannen, der seit 1505/6 in Nürnberg arbeitete und später in Nördlingen tätig war. Die Darstellung entstand im Jahr 1517 zur Illustration des Andachtsbuchs Himmelwagen-Hellwagen des Johannes von Leonhardt und zeigt einen Mann, der einen Fluß auf einer Brücke oder einem schmalen Steg überquert und von einer Landschaft in eine andere schreitet.

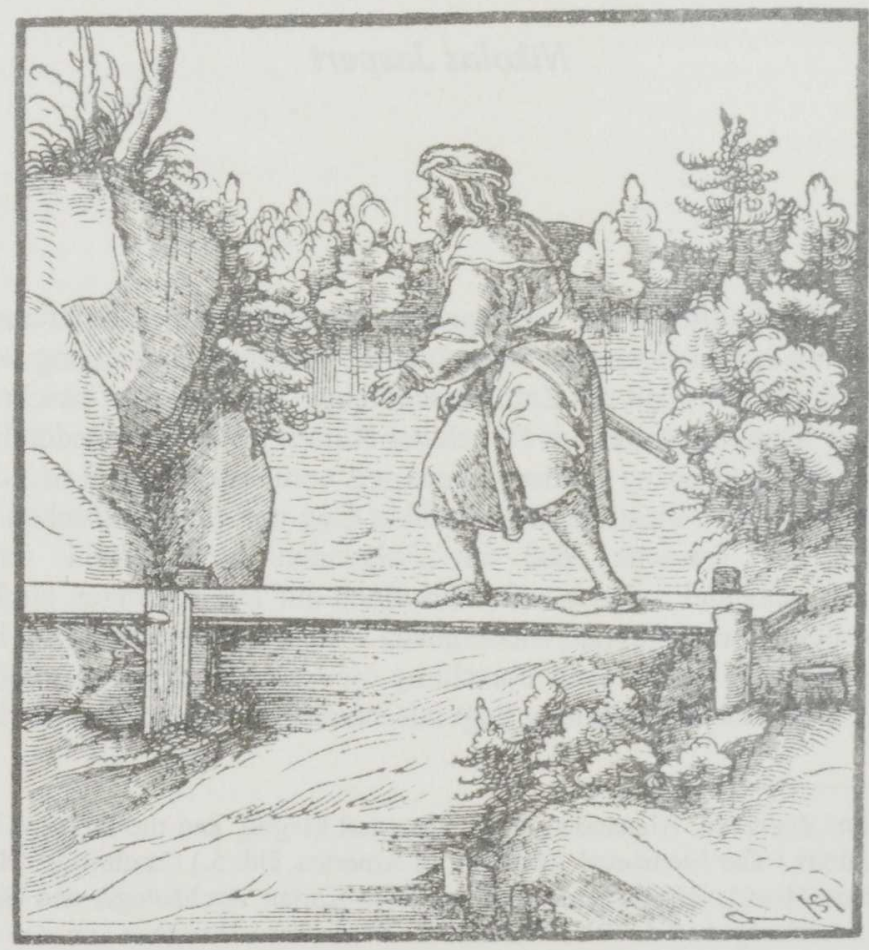

Hans Schäufelein: Der Mensch auf einem schmalen Steg (1517), aus: Johannes von Leonhardt, Himmelwagen - Hellwagen, Bl. C $2 r^{3}$

Wählt man diesen Holzschnitt als Sinnbild für mittelalterliche Grenzräume und Grenzüberschreitungen, so scheint man zugleich Stellung bezogen und sich einer Definition dessen

Schäufeleins von Nürnberg über Meran nach Augsburg, in: Hans Schäufelein. Vorträge gehalten anläßlich des Nördlinger Symposiums im Rahmen der 7. Rieser Kulturtage in der Zeit vom 14. Mai bis 15. Mai 1988. Nördlingen 1990, 240-272 zeigt den Künstler als Grenzgänger.

3 Nach: Karl Heinz Schreyl, Hans Leonhard Schäufelein: Das druckgraphische Werk, 2 Bde. Nördlingen 1990, Bd. II, Nr. 850; zur Datierung vgl. Bd. I, 143 f. 
angeschlossen zu haben, was eigentlich eine Grenze sei. Daß in dieser Frage keineswegs Einigkeit herrscht und gerade in den letzten Jahren innerhalb der einzelnen Geisteswissenschaften und zwischen ihnen verstärkt um Verständnis, Funktion und Definition der Grenze gerungen worden ist, macht zugleich die Herausforderung und den Reiz des Themas aus. Es mag lohnenswert sein, unterschiedliche Grenzdeutungen vorzustellen und diese in neuere Forschungszusammenhänge zu stellen - nicht zuletzt, um die Beiträge dieses Bandes in die laufende Diskussion einordnen zu können und sich darüber Klarheit zu verschaffen, was mit dieser Aufsatzsammlung geleistet und was nicht erwartet werden kann oder soll.

\section{Säume, Linien und Grenzerfahrungen}

Der Wanderer auf dem Schäufeleinschen Holzschnitt überschreitet eine klar zu erkennende Linie. Doch gab es im Mittelalter überhaupt solch klare Grenzziehungen? Entstand die Grenzlinie nicht grundsätzlich im Zuge eines lang andauernden, allmählichen Prozesses aus dem Grenzsaum, um den Titel eines einflußreichen Werkes Hans-Jürgen Karps abzuwandeln? $?^{4}$ Die neuere Forschung verneint diese Frage, und zwar gerade mit dem Hinweis auf Quellen aus dem mitteleuropäischen Raum. ${ }^{5}$ Nahm die ältere Forschung noch an, daß im Früh- und Hochmittelalter lediglich vage Grenzräume existierten, die im Laufe des 13. bis 15. Jahrhunderts im Zuge zunehmender „Verstaatlichung“ zu linearen Grenzen verengt wurden, haben jüngere Arbeit mit Recht frühmittelalterliche Grenzbeschreibungen herangezogen, um zu belegen, daß bereits im 8 . bis 11 . Jahrhundert direkte Verbindungen zwischen zwei Orientierungspunkten bezeichnet wurden, um Gebiete voneinander zu scheiden. ${ }^{6}$ Quasi recta via, recta estimationis linea und vergleichbare Formulierungen lassen erkennen, daß bereits zu dieser Zeit gerade Grenzlinien zumindest gedacht wurden, und die Erwähnungen von Grenzsteinen und Markierungen ab dem 12. Jahrhundert belegen, daß

4 Hans-Jürgen Karp, Grenzen in Ostmitteleuropa während des Mittelalters: ein Beitrag zur Entstehungsgeschichte der Grenzlinie aus dem Grenzsaum. (Forschungen und Quellen zur Kirchenund Kulturgeschichte Ostdeutschlands, Bd. 9.) Köln [u.a.] 1972. Karp griff damit eine Formulierung Hans Helmolts aus dem Jahre 1896 auf: Hans F. Helmolt, Die Entwickelung der Grenzlinie aus dem Grenzsaume im alten Deutschland, in: Historisches Jahrbuch 17, 1896, 235-264.

5 Dies aus Guy P. Marchal, Grenzerfahrung und Raumvorstellungen: Zur Thematik des Kolloquiums, in: Guy P. Marchal (Hrsg.), Grenzen und Raumvorstellungen: (11.-20. Jh.) = Frontières et conceptions de l'espace. (Clio Lucernensis, Bd. 3.) Zürich 1996, 11-25, 14 mit Literatur S. 23 f.; vgl. auch Luciano Lagazzi, Segni sulla terra: determinazione dei confini e percezione dello spazio nell'alto Medioevo. (Biblioteca di storia agraria medievale, Bd. 8.) Bologna 1991, 13-50.

6 Reinhard Bauer, Die ältesten Grenzbeschreibungen in Bayern und ihre Aussagen für Namenkunde und Geschichte. (Die Flurnamen Bayerns, Bd. 8.) München 1988; Friedhelm Debus / Reinhard Bauer (Hrsg.), Frühmittelalterliche Grenzbeschreibungen und Namenforschung. (Beiträge zur Namenforschung. Beiheft, Bd. 42.) Heidelberg 1992; Matthias Hardt, Linien und Säume, Zonen und Räume an der Ostgrenze des Reiches im frühen und hohen Mittelalter, in: Grenze und Differenz im frühen Mittelalter. (Forschungen zur Geschichte des Mittelalters, Bd. 1 = Österreichische Akademie der Wissenschaften, Philosophisch-historische Klasse, Bd. 287.) Wien 2000, 39-56; David Griffiths / Andrew Reynolds / Sarah Semple (Hrsg.), Boundaries in Early Medieval Britain. (Anglo-Saxon Studies in Archaeology and History, Bd. 12.) Oxford 2003. 
solche präzisen Linien auch gezogen worden sind. ${ }^{7}$ Menschliche, aber auch natürliche Markierungen wie Felsen, Bäume, Sümpfe etc. wurden als Eckpunkte benutzt, um Räume unmißverständlich voneinander zu scheiden. ${ }^{8}$ Dieser aufgrund von mitteleuropäischen und italienischen Quellen erzielte Befund ist durch iberische Texte zu bereichern, denn gerade in den christlichen Reichen der Iberischen Halbinsel wurden Regionen vertraglich voneinander geschieden und dabei klare Trennungslinien angegeben. Am eindrücklichsten geschah dies in einer Reihe von Verträgen, in denen christliche Herrscher zukünftige Eroberungsräume aufteilten. Die Verträge von Tudilén 1151, von Cazola 1179 und von Almizra 1244 legten immer genauer bezeichnete Grenzlinien fest und können den vorwiegend aus kleinräumigen Beispielen abgeleiteten mitteleuropäischen Befund auch für größere Räume bestätigen. Allerdings wird an diesen Dokumenten zugleich erkennbar, daß solche Herrschaftsbegrenzungen - wohl notgedrungen - unpräziser wurden, je größer die abgesteckten Territorien waren.

Die Entstehung von politischen Grenzen ist also weniger regelhaft als die ältere Forschung annahm, die Verdichtung eines Grenzraums zur Grenzlinie läßt sich im Mittelalter ebenso feststellen wie die Ausweitung der Grenzlinie zum Grenzsaum, die Verfestigung der Scheidelinien ebenso wie ihre Auflösung. ${ }^{10}$ Herrschaftsgrenzen konnten aus versprengten Herrschaftspunkten bestehen, die räumlich sogar auf dem Gebiet des Nachbarn lagen und lediglich in den Augen moderner Betrachter zu Linien miteinander verbunden werden. ${ }^{11}$ Es lassen sich aber ebenso - etwa an den Grenzen Ungarns - markierte, befestigte Reichsgrenzen feststellen, an denen etwa Abgaben und Zölle zu leisten waren. ${ }^{12}$

7 Marchal, Grenzerfahrung und Raumvorstellungen (wie Anm. 5), 14 f.; Hans Werner Nicklis, Von der "Grenitze" zur Grenze. Die Grenzidee des lateinischen Mittelalters, in: Blätter für deutsche Landesgeschichte 128, 1992, 1-29, 3-5, 12; Lagazzi, Segni sulla terra (wie Anm. 5).

8 Beispiele für naturräumliche Markierungen u.a. bei Reinhard Schneider, Grenzen und Grenzziehung im Mittelalter, in: Wolfgang Brücher / Peter Robert Franke (Hrsg.), Probleme von Grenzregionen. Saarbrücken 1987, 9-27; Helmut Maurer, Naturwahrnehmung und Grenzbeschreibung im hohen Mittelalter. Beobachtungen an italienischen Quellen, in: Karl Borchardt / Enno Bünz (Hrsg.), Forschungen zur Reichs-, Papst- und Landesgeschichte. Peter Herde zum 65. Geburtstag, Bd. 1. Stuttgart 1998, 239-253, 243-250; vgl. auch die Beiträge in Marchal (Hrsg.), Grenzen und Raumvorstellungen (wie Anm. 5).

9 Nora Berend, Medievalists and the Notion of the Frontier, in: The Medieval History Journal 2, 1999, 55-72, 69; Pierre Guichard, Avant Tordesillas: La délimitation des terres de reconquête dans l'Espagne des XII ${ }^{\mathrm{e}}$ et XIII ${ }^{\mathrm{e}}$ siècles, in: Michel Balard / Alain Ducellier (Hrsg.), Le partage du monde: échanges et colonisation dans la méditerranée médiévale. (Série Byzantina Sorbonensia, Bd. 17.) Paris $1998,453-460$.

10 Daniel Power / Naomi Standen, Introduction, in: Daniel Power/ Naomi Standen (Hrsg.), Frontiers in question: Eurasian borderlands, 700-1700. Houndmills [u.a.] 1999, 1-31, 4-5.

11 So Ronnie Ellenblum, Were there borders and borderlines in the Middle Ages? The example of the latin kingdom of Jerusalem, in: David Abulafia / Nora Berend (Hrsg.), Medieval frontiers: concepts and practices. Aldershot [u.a.] 2002, 105-119.

12 Beispiel Ungarn von Nora Berend, Hungary, "the gate of christendom", in: Abulafia/ Berend (Hrsg.), Medieval frontiers (wie Anm. 11), 195-215, 201-205. 
Wieviel von alledem war den Zeitgenossen aber bewußt? Welche Vorstellungen dürften mittelalterliche Menschen von der Grenze gehabt haben? Neuere Arbeiten haben zu ergründen versucht, ob und, wenn $\mathrm{ja}$, wie diese Trennlinien wahrgenommen wurden. ${ }^{13}$ Wie erkannten Menschen in einer kartenlosen, technisch rückständigen Zeit voller unerschlossener Räume, daß sie Grenzlinien überschritten? Waren ,,kleine Grenzen“ - Flur-, Pfarroder Gemeindegrenzen - nicht wichtiger als ,große“, also politische Scheidelinien? ${ }^{14}$ Paul Zumthor, Luciano Lagazzi und andere haben das Raumgefühl mittelalterlicher Menschen, die „Mesure du monde“, zu erfassen versucht und vielfältige, sich mitunter auch überschneidende Grenzen definiert ${ }^{15}$, während andere Forscher weniger danach gefragt haben, wie Zeitgenossen Grenzen empfanden, als vielmehr, auf welche Weise sie diese beurteilten. Letzteres läßt sich für weite Teile der Bevölkerung nicht bestimmen, doch mancher Kleriker äußerte sich sehr wohl zu dieser Frage. Auch wenn die Kirche selbst an der Schaffung und Festigung von Grenzen beteiligt war: theologisch betrachtet stellten diese eine verderbliche, wenn auch notwendige Einrichtung dar ${ }^{16}$, waren sie doch ein Ergebnis frühester Sünden der Menschen. Kains Nachfolger waren bekanntlich die ersten, die Städte gründeten und diese durch Befestigungen von ihrer Umwelt abgrenzten. Die Ermordung Abels legte

13 Vgl. die Beiträge in Marchal, Grenzen und Raumvorstellungen (wie Anm. 5), vor allem die luzide Einführung: Marchal, Grenzerfahrung und Raumvorstellungen: Zur Thematik des Kolloquiums, ebd., 11-25; Maurer, Naturwahrnehmung und Grenzbeschreibung im hohen Mittelalter (wie Anm. 8); Pascal Buresi, Nommer, penser les frontières en Espagne aux $\mathrm{XI}^{\mathrm{e}}-\mathrm{XII}^{\mathrm{e}}$ siècles, in: Carlos de Ayala Martínez / Pascal Buresi / Philippe Josserand (Hrsg.), Identidad y representación de la frontera en la España medieval (siglos XI-XIV). (Collection de la Casa de Velázquez, Bd. 75.) Madrid 2001, 51-74

14 Patrick Gautier Dalché, Un problème d'histoire culturelle. Perception et représentation de l'espace au Moyen Age, in: Médiévales. Langage, textes, histoire 18, 1990, 5-15; Marchal, Grenzerfahrung und Raumvorstellungen: Zur Thematik des Kolloquiums (wie Anm. 13), 19. Kleinräumige Abgrenzungen und ihre Begrifflichkeit untersucht u. a. Harald Siems, Flurgrenzen und Grenzmarkierungen in den Stammesrechten, in: Heinrich Beck / Dietrich Denecke / Herbert Jankuhn (Hrsg.), Untersuchungen zur eisenzeitlichen und frühmittelalterlichen Flur. Göttingen 1980, 267-309.

15 Paul Zumthor, La mesure du monde: représentation de l'espace au Moyen Âge. Paris 1993; Lagazzi, Segni sulla terra (wie Anm. 5). Vgl. Auch Marchal, Grenzerfahrung und Raumvorstellungen: Zur Thematik des Kolloquiums (wie Anm. 13) und Maurer, Naturwahrnehmung und Grenzbeschreibung im hohen Mittelalter (wie Anm. 8); Carlos Gozalbes Cravioto, Reflexiones sobre el concepto antiguo y medieval de frontera, in: III Estudios de frontera. Convivencia, defensa y comunicación en la frontera. En memoria de Don Juan de Mata Carriazo y Arroquia. Alcalá la Real, 1999. Jaén 2000, 361-374.

16 Zur kirchlichen Grenzziehung siehe Antonio Linage Conde, La geografia eclesiástica y la frontera, in: III Estudios de frontera (wie Anm. 15), 413-426, unten die Aufsätze und Literaturangaben von Luís Martín Martín und Jerzy Strzelczyk in diesem Band sowie die Gesamtschau von Hans Joachim Schmidt: Hans-Joachim Schmidt, Kirche, Staat, Nation: Raumgliederung der Kirche im mittelalterlichen Europa. (Forschungen zur mittelalterlichen Geschichte, Bd. 37.) Weimar 1999. In Kürze ergänzend: Klaus Herbers, Religions et frontières, in: Outi Merisalo (Hrsg.), Frontiers in the Middle Ages: Proceedings of the Third European Congress of Medieval Studies (Jyväskylä, 10-14 June 2003). (Textes et études du Moyen Âge, Bd. 35.) Turnhout 2006, 703-716. 
den Grund für Privatbesitz und damit letztlich auch für die Abgrenzung zwischen den Menschen. Daß die Kirche selbst Grenzziehungen betrieb, bedurfte daher der Rechtfertigung. Rupert von Deutz, Gervasius von Tilbury und andere hochmittelalterliche Gelehrte und Theologen lieferten sie, indem sie darauf hinwiesen, daß die Kirche mit ihrer Raumeinteilung lediglich den Schwächen der civitas terrena folge, der sie nun einmal angehöre. ${ }^{17}$

Die Abgrenzung als Folge menschlicher Sünde war auch das Thema einer weiteren Stelle des Alten Testaments, der ein Erlanger Mediävist sechs voluminöse, zu wenig beachtete Bände gewidmet hat. ${ }^{18}$ Gemeint ist der Turmbau zu Babel (Genesis 11,1-9), jener Schlüsselmoment menschlicher Entfremdung und Kommunikationslosigkeit, in dem Gott seine Geschöpfe voneinander absetzte. Sprach- und Kulturgrenzen vergangener Zeiten „kulturelle Isoglossen“, wie es Jürgen Lang in seinem Beitrag formuliert ${ }^{19}$ - sind oftmals schwer zu bestimmen, doch zweifellos außerordentlich wirkungsvoll gewesen. Daß sie jedoch hermetisch gewesen seien, kann man mit Fug und Recht verneinen, wie auch Beiträge dieses Bandes verdeutlichen: In den Grenzräumen bildeten sich nicht nur fremdsprachliche Expertise, sondern auch Mechanismen und Instrumente des Spracherwerbs aus. $^{20}$

Das elfte Kapitel der Genesis verweist auf einen weiteren Bedeutungsgehalt des Wortes Grenze: Scheidungen existieren bekanntlich auch innerhalb ein und derselben Gesellschaft, zwischen den Ständen, den Geschlechtern etc. - aber auch innerhalb eines Individuums, wie das geläufige Wort von der Grenze im Kopf andeutet. ${ }^{21}$ Wo man auch hinschaut oder -geht,

17 Rupertus Tuitiensis, De sancta trinitate et operibus eius, Bd. 1, Hrabanus Haacke (Hrsg.). (Corpus Christianorum. Continuatio Mediaevalis, Bd. 21.) Turnhout 1971, 294; Gervasius Tilberiensis - Gervasius of Tilbury, Otia imperialia = Recreation for an emperor. Oxford [u.a.] 2002; vgl. Hans Joachim Schmidt, Grenzen in der mittelalterlichen Kirche. Ekklesiologische und juristische Konzepte, in: Marchal (Hrsg.), Grenzen und Raumvorstellungen (wie Anm. 5), 137-162, bes. 153 f.; José María Soto Rábanos, La frontera. Conotaciones jurídico-canónicas (siglos XII-XV), in: Pedro Segura Artero (Hrsg.), Actas del Congreso La Frontera Oriental Nazarí como Sujeto Histórico, (s. XIII-XVI): Lorca - Vera, 22 a 24 de noviembre de 1994. (Instituto de Estudios Almerienses: Colección Actas, Bd. 29.) Sevilla 1997, 213-220. Zu den himmlischen Grenzen aus althistorischer Perspektive besonders die Beiträge in Aline Rousselle (Hrsg.), Frontières terrestres, frontières célestes dans l'antiquité. (Collection Études, Bd. 20.) Perpignan 1995, auf S. 297-386.

18 Arno Borst, Der Turmbau von Babel: Geschichte der Meinungen über Ursprung und Vielfalt der Sprachen und Völker, 6 Vol. in 5 Bden. München 1957-1963; vgl. auch Jasper Liptow, Grenzen sprachlicher Verständigung - Zum Problem des Sprachenrelativismus, in: Wolfram Hogrebe / Joachim Bromand (Hrsg.), Grenzen und Grenzüberschreitungen: XIX. Deutscher Kongress für Philosophie, Bonn, 23.-27. September 2002. Vorträge und Kolloquien. Berlin 2004, 209-220.

19 Vgl. unten, S. 292. Siehe zum allgemeinen Rahmen: Jürgen Osterhammel, Kulturelle Grenzen in der Expansion Europas, in: Saeculum 45, 1995, 101-138.

20 Vgl. unten die Aufsätze und Literaturangaben von Jürgen Lang, Christiane Schiller, Andreas Rüther und Felicitas Schmieder in diesem Band. Siehe auch unten die Infragestellung einer reduktionistischen Deutung der Sprachgrenze bei Matthias Maser.

21 Cristina Segura Graiño, Una reflexión sobre las fronteras en la Edad Media: implicaciones sociales, políticas y mentales, in: Aragón en la Edad Media 15, 1999, 1487-1499, 1490-1494. Vgl. etwa verschiedene Beiträge in Diagonal. Zeitschrift der Universität-Gesamthochschule Sie- 
überall verlaufen unterschiedlich alte, mit verschiedenen Sinnen erfaßbare Grenzen. ${ }^{22}$ Hier betreten wir den Zwischenraum zwischen Sozialgeschichte und der Geschichte der Vorstellungen. Daß solche Vorstellungsgrenzen nicht weniger bedeutsam waren und sind als die im Grunde ebenfalls mental gezogenen - politischen Grenzen, daß sie sogar größere Wirksamkeit als diese entfalten konnten und können, muß nicht eigens betont werden. Doch verlassen wir mit diesem Sinngehalt des Wortes bereits den festen räumlichen Boden, der dem vorliegenden Sammelband über das mittelalterliche Ostmittel- und Südwesteuropa zugrunde liegt.

\section{Flüsse, Berge und die Politik der Grenzforschung}

Kehren wir daher wieder zu unserem Holzschnitt zurück, denn er führt uns zu einer weiteren Bedeutungsebene des Grenzbegriffs. Der Wanderer überschreitet nämlich keine feste, lineare, sondern eine sogenannte „nasse Grenze“, einen Fluß. Das mag auf den ersten Blick nicht erstaunen, werden doch heutzutage eine Vielzahl politischer Grenzen durch Flußläufe markiert. Auch im Mittelalter gab es genügende derartiger ,nasser Grenzen“, denn natürliche und politische Scheidelinien standen stets in engem Verhältnis zueinander. ${ }^{23}$ Doch ist

gen, Jahrgang 1993, Heft 2; Ehrhardt Cremers, Relativität der Grenze - Grenzen der Relativität: über das Bewußtsein einer lebensweltlichen Herausforderung. (Aachener Studien zur Semiotik und Kommunikationsforschung, Bd. 13.) Aachen 1990; Markus Bauer/Thomas Rahn (Hrsg.), Die Grenze: Begriff und Inszenierung. Berlin 1997; Hogrebe/ Bromand (Hrsg.), Grenzen und Grenzüberschreitungen (wie Anm. 18). Eine Übertragung des Bildes auf den historischpolitischen Bereich nimmt vor: Peter Haslinger (Hrsg.), Grenze im Kopf: Beiträge zur Geschichte der Grenze in Ostmitteleuropa. (Wiener Osteuropa-Studien, Bd. 11.) Frankfurt am Main [u.a.] 1999; Bernard Fouques (Hrsg.), A propos de frontière: variations socio-critiques sur les notions de limite et de passage. (Liminaires - passages interculturels italo-ibériques, Bd. 2.) Bern [u.a.] 2003

22 Zur Universalität und Beliebigkeit der Grenze: Cremers, Relativität der Grenze - Grenzen der Relativität (wie Anm. 21), 9-15.

23 Vgl. Schneider, Grenzen und Grenzziehung im Mittelalter (wie Anm. 8); Franz Irsigler, Der Einfluß politischer Grenzen auf die Siedlungs- und Kulturlandschaftsentwicklung. Eine Einführung in die Tagungsthematik, in: Siedlungsforschung. Archäologie-Geschichte-Geographie 9, 1991, 9-21, 16; Maurer, Naturwahrnehmung und Grenzbeschreibung im hohen Mittelalter (wie Anm. 8), 247-250; María J. Latorre Rodríguez, El agua como frontera, in: Francisco Toro Ceballos / José Rodríguez Molina (Hrsg.), IV Estudios de Frontera: Historia, tradiciones y leyendas en la frontera. Congreso celebrado en Alcalá la Real en noviembre de 2001. Homenaje a Don Enrique Toral y Peñaranda. Jaén 2002, 311-324; Jürgen Schneider (Hrsg.), Natürliche und politische Grenzen als soziale und wirtschaftliche Herausforderung: Referate der 19. Arbeitstagung der Gesellschaft für Sozial- und Wirtschaftsgeschichte vom 18. bis 20. April 2001 in Aachen. (Vierteljahrschrift für Sozial- und Wirtschaftsgeschichte: Beihefte, Bd. 166.) Stuttgart 2003; Société des Historiens Médiévistes de l'Enseignement Supérieur Public (Hrsg.), Montagnes médiévales: XXXIV congrès de la SHMES, (Chambéry, 23-25 mai 2003). (Série histoire ancienne et médiévale. Paris 2004; und zur antiken Frühgeschichte Rousselle (Hrsg.), Frontières terrestres (wie Anm. 17), darin besonders Georges Castellvi, "Clausurae" (les Cluses, Pyrénées orientales): fortresses frontières du Bas-Empire, 81-119. 
hier zugleich Vorsicht geboten. Die Vorstellung von vermeintlich „,natürlichen“, topographisch geprägten Grenzen diente in moderner Zeit oft genug als Argument für militärische Expansion, man denke nur an den Drang zur Rheingrenze unter Richelieu. ${ }^{24}$ Eine nüchterne Sichtung der Quellen zeigt, daß Grenzlinien im Mittelalter keineswegs immer durch Flüsse gebildet wurden. ${ }^{25}$ Ähnliches gilt auch für Gebirgskämme, eine weitere beliebte Scheide der Moderne. Das frühmittelalterliche Herzogtum Bayern in den Alpen oder die Krone Aragón in den Pyrenäen mögen als Beispiele dafür dienen, daß beiderseits von Gebirgszügen sich erstreckende Herrschaften im Mittelalter keine Seltenheit waren. ${ }^{26}$

Am Argument der natürlichen Staatsgrenzen wird ersichtlich, daß unser Thema in der Forschungsgeschichte stets einen starken Gegenwartsbezug aufgewiesen hat. Auch und gerade grundlegende ältere, der nationalen Geschichtsschreibung verpflichtete Studien wie die Arbeiten Friedrich Ratzels zur politischen Geographie oder Paul Kirns zur Geschichte der deutschen Grenze ${ }^{27}$ sind vor dieser Prämisse zu sehen, ebenso jedoch die jüngere Beschäftigung mit dem Gegenstand. ${ }^{28}$ Dies muß im Grunde für Ostmitteleuropa nicht eigens betont werden, wo deutsche, polnische, tschechische und russische Historikerinnen und Historiker viele Jahrzehnte lang um historische Begründungen für aktuelle Grenzverschiebungen gestritten haben. ${ }^{29}$ Aktuelle Ereignisse und Entwicklungen haben ohne Zweifel

24 Norman J. Pounds, France and "les limites naturelles" from the Seventeenth to the Twentieth Centuries, in: Annals of the Association of American Geographers 44, 1954, 51-62; Peter Sahlins, Boundaries: the making of France and Spain in the Pyrenees. Los Angeles 1989; Schneider, Natürliche und politische Grenzen (wie Anm. 23).

25 Power/Standen, Introduction (wie Anm. 10), 6 mit Anm. 20; Walter Pohl, Soziale Grenzen und Spielräume der Macht, in: Pohl / Reimitz (Hrsg.), Grenze und Differenz im frühen Mittelalter (wie Anm. 6), 11-18, 12-13; Joaquín Lomba Fuentes, El Ebro, puente de Europa: pensamiento musulmán y judío. Zaragoza 2002.

26 Jaume Bertranpetit/Elisenda Vives (Hrsg.), Muntanyes i població. El passat dels Pirineus des d'una perspectiva multidisciplinaria. Andorra 1995; Antonio Linage Conde, Antecedentes del europeísmo: el Pirineo y la frontera en la Edad Media, in: Actas del III Congreso Internacional de Historia Militar. (Publicaciones de la Institución Fernando el Católico, Bd. 1832.) Zaragoza 1997, 569-574; Serge Brunet, Les Pyrénées: Genèse de la frontière et adaptations locales par des accords transfrontaliers (XIV $-\mathrm{XVIII}{ }^{\mathrm{e}}$ siècle), in: Schneider (Hrsg.), Natürliche und politische Grenzen (wie Anm. 23), 69-94; Johann Holzner / Elisabeth Walde (Hrsg.), Brüche und Brücken: Kulturtransfer im Alpenraum von der Steinzeit bis zur Gegenwart. (Transfer, Bd. 57.) Bozen 2005 .

27 Friedrich Ratzel, Politische Geographie. München 1897; Paul Kirn, Politische Geschichte der deutschen Grenzen. Leipzig 1934.

28 Vgl. Berend, Medievalists and the Notion of the Frontier (wie Anm. 9); Rebekka Habermas $/$ Rebekka von Mallinckrodt, Interkultureller Transfer und nationaler Eigensinn: Europäische und anglo-amerikanische Positionen der Kulturwissenschaften. Göttingen 2004.

29 Jan M. Piskorski (Hrsg.), Historiographical approaches to medieval colonization of East Central Europe: a comparative analysis against the background of other European inter-ethnic colonization processes in the Middle Ages. (East European monographs, Bd. 611.) Boulder, Colo. 2002, und als historiographische Überblicke: Jan M. Piskorski, After Occidentalism: The Third Europe Writes its own History (Instead of an Introduction), ebd. 7-23; The Medieval 'Colonization of the East' in Polish Historiography, ebd., 97-105, sowie von demselben Autor: The Medieval Coloni- 
ihren Teil dazu beigetragen, daß die Grenzthematik in den letzten Jahren intensiver als zuvor untersucht worden ist. So bedingten der deutsche Einigungsprozeß nach 1989 und die in jenen Jahren vollzogenen Grenzveränderungen eine Reihe von Publikationen. ${ }^{30}$ Zur Zeit erleben wir die auf den ersten Blick paradoxe Situation, daß gerade in einem Moment, in der Nationalgrenzen im Zuge der sogenannten Globalisierung ${ }^{31}$ an Bedeutung zu verlieren scheinen, das Thema der Grenze in der Forschung intensive Beachtung findet. ${ }^{32}$ Doch bei

zation of Central Europe as a Problem of World History and Historiography, in: German History 22, 2004, 323-343; vgl. Dorota Leśniewska, Kolonizacja niemiecka i na prawie niemieckim w średniowiecznych Czechach i na Morawach w świetle historiografii. Poznań/ Marburg 2004; sowie schon die treffsichere Bestandsaufnahme aus dem Jahre 1975: Klaus Zernack, Zusammenfassung: Die hochmittelalterliche Kolonisation in Ostmitteleuropa und ihre Stellung in der europäischen Geschichte, in: Walter Schlesinger (Hrsg.), Die deutsche Ostsiedlung des Mittelalters als Problem der europäischen Geschichte: Reichenau-Vorträge 1970-1972. (Vorträge und Forschungen, Bd. 18.) Sigmaringen 1975, 783-804 und zuvor die Übersicht von Gerard Labuda, Polska granica zachodnia. Poznan 1971. Zur deutschen Perspektive siehe auch Jörg Hackmann I Christian Lübke, Die mittelalterliche Ostsiedlung in der deutschen Geschichtswissenschaft, in: Piskorski (Hrsg.), Historiographical approaches (wie oben), 179-217.

30 Wilfried Heller, Politische Grenzen und Grenzziehungen aus anthropogeographischer Sicht, in: Bernd Weisbrod (Hrsg.), Grenzland. Beiträge zur Geschichte der deutsch-deutschen Grenze. Hannover 1993, 173-193, 173 gibt eine Übersicht über die zwischen 1989 und 1991 gegründeten Forschungseinrichtungen, die sich dem Thema widmen; vgl. auch die Sammelbände: Alexander Demandt / Reimer Hansen (Hrsg.), Deutschlands Grenzen in der Geschichte. München 1990; Wolfgang Haubrichs / Reinhard Schneider (Hrsg.), Grenzen und Grenzregionen = Frontières et régions frontalières. (Veröffentlichungen der Kommission für Saarländische Landesgeschichte und Volksforschung, Bd. 22.) Saarbrücken 1993; Richard Faber (Hrsg.), Literatur der Grenze Theorie der Grenze. Würzburg 1995. Laut Hans-Werner Nicklis wurde sein Beitrag: „...durch die bewegenden Bilder der innerdeutschen Grenzöffnung im Herbst 1989 inspiriert" - Nicklis, Von der "Grenitze" zur Grenze (wie Anm. 7), 1.

31 Vgl. die kurze Übersicht: Jürgen Osterhammel / Niels P. Petersson, Geschichte der Globalisierung: Dimensionen, Prozesse, Epochen. (Beck'sche Reihe, Bd. 2320.) München 2004 und die Beiträge in: Paul Nolte / Jürgen Osterhammel (Hrsg.), Globalisierungen, in: Geschichte und Gesellschaft 31, 2005, 506-637.

32 Michael J. Shapiro (Hrsg.), Challenging boundaries: global flows, territorial identities. (Borderlines, Bd. 2.) Minneapolis, Minn. [u.a.] 1996; Karl S. Guthke, Die Erfindung der Welt: Globalität und Grenzen in der Kulturgeschichte der Literatur. (Edition Patmos, Bd. 11.) Tübingen 2005. An neueren Sammelbänden seien weiterhin genannt: Michel Poisson (Hrsg.), Frontière et peuplement dans le monde méditerranéen au Moyen Âge. Actes du colloque d'Erice - Trapani (Italie) tenu du 18 au 25 septembre 1988. (Castrum 4. Collection de la Casa de Velázquez, Bd. 38. Collection de l'École Française de Rome, Bd. 105.) Roma 1992; Leonardo Benevolo / Benno Albrecht, Grenzen. Typographie - Geschichte - Architektur. Frankfurt 1995; Bauer / Rahn (Hrsg.), Die Grenze (wie Anm. 21); Power / Standen (Hrsg.), Frontiers in question (wie Anm. 10); De Ayala Martínez / Buresi / Josserand (Hrsg.), Identidad y representación de la frontera (wie Anm. 13); Abulafia / Berend (Hrsg.), Medieval frontiers (wie Anm. 11); Allen Buchanan/Margaret Moore (Hrsg.), States, nations, and borders: the ethics of making boundaries. Cambridge 2003; Florin Curta (Hrsg.), Borders, barriers, and ethnogenesis: frontiers in Late Antiquity and the Middle Ages. (Studies in the early Middle Ages, Bd. 12.) Turnhout 2005; Joachim Becker 
näherem Hinsehen ist dies wenig verwunderlich, führte doch das Streben nach Vereinheitlichung und Einigung bekanntlich häufig zu neuer Binnendifferenzierung. Ein gutes Beispiel für dieses Phänomen ist der europäische Einigungsprozeß, der mit einer gewissen zeitlichen Verzögerung dem Konzept eines „Europa der Regionen“ Auftrieb gegeben hat. Während alte, nationale Grenzen abgeschafft werden, werden ältere Kultur-, Raum- und Sprachgrenzen aufgewertet. Und während in einem Großraum politische Grenzen an Bedeutung verlieren, werden in anderen Scheidelinien neu geschaffen oder zementiert - und dies durchaus im eigentlichen Sinne des Wortes, wie die jüngste Errichtung physischer Barrieren im Nahen Osten belegt.

Damit berühren wir eine weitere, weniger politisch und verfassungsgeschichtlich als sozial- und gesellschaftshistorisch verstandene Deutung der Grenze. Sie ist nicht nur als gerade Trennlinie im Raum und als Abschluß zweier politischer Gebilde, sondern durchaus auch als Abschottung von Großgruppen nach außen zu begreifen. Wo sie endet, beginnt das Fremde. Die Grenzthematik hat daher eine fremdheitsgeschichtliche - oder „xenologische“ - Dimension. ${ }^{33}$ In der Tat trug und trägt die Grenze dazu bei, beides - Eigenes und Fremdes, Wir und Sie - voneinander zu scheiden, sie hat damit eine identitätsstiftende Funktion und wirkt auf die Vorstellungswelt derer, die sie umschließt. Ältere Forschungen haben längst belegt, daß berühmte Grenzbefestigungen, ja sogar die berühmteste aller Grenzbefestigungen, die Große Chinesische Mauer, eher konsolidierende Wirkung nach innen als abwehrende Funktion nach außen besaßen. ${ }^{34}$ Gerade die Glaubensgrenze, wie sie im Mittelalter im Südwesten und im Osten Europas vorlag, trug wesentlich zu dieser Form der Eigensicht in Absetzung vom Anderen bei, wie die Beispiele Kastiliens, Portugals, Polens und Ungarns zeigen. ${ }^{35}$

(Hrsg.), Grenzen weltweit: Zonen, Linien, Mauern im historischen Vergleich. (Historische Sozialkunde, Bd. 15.) Wien 2006.

33 Dagmar Stutzinger / Harry Kühnel / Albrecht Classen, Das Fremde und das Eigene, in: Peter Dinzelbacher (Hrsg.), Europäische Mentalitätsgeschichte. Hauptthemen in Einzeldarstellungen. Stuttgart 1993, 400-450; Klaus J. Bade, Einführung: Das Eigene und das Fremde - Grenzerfahrungen in Geschichte und Gegenwart, in: Klaus J. Bade (Hrsg.), Deutsche im Ausland - Fremde in Deutschland. Migration in Geschichte und Gegenwart. München 1992, 15-25; Dietrich Harth (Hrsg.), Fiktion des Fremden. Erkundungen kultureller Grenzen in Literatur und Publizistik. Frankfurt am Main 1994; Bernhard Waldenfels, Phänomenologie des Eigenen und des Fremden, in: Herfried Münkler / Bernd Ladwig (Hrsg.), Furcht und Faszination. Facetten der Fremdheit. Berlin 1997, 65-84; Hastings Donnan / Thomas M. Wilson (Hrsg.), Borders: frontiers of identity, nation and state. Oxford [u.a.] 1999; Pohl / Reimitz (Hrsg.), Grenze und Differenz im frühen Mittelalter (wie Anm. 6); Wolfgang Eßbach (Hrsg.), Wir - Ihr - Sie. Identität und Alterität in Theorie und Methode. (Identitäten und Alteritäten, Bd. 2.) Würzburg 2001.

34 Owen Lattimore, Origins of the Great Wall of China: A Frontier Concept in Theory and Practice, in: Geographical Review 27, 1937, 529-549, vgl. Berend, Medievalists and the Notion of the Frontier (wie Anm. 9), 60. Vgl. Matthias Masers in diesem Band formulierte Gedanken zur Rolle der Grenze für das Selbstverständnis der Christen im mittelalterlichen Spanien.

35 Oskar Halecki, Grenzraum des Abendlandes: eine Geschichte Ostmitteleuropas, Salzburg 1952; Paul W. Knoll, Poland as 'antemurale Christianitatis' in the Late Middle Ages, in: The Catholic Historical Review 60, 1974, 381-401; Mikel de Epalza, El islam aragonés, un islam de frontera, 
Es kann daher nicht wirklich überraschen, dass die Rhetorik des Fremden ein elementarer Bestandteil der Grenze ist. Zur Absetzung vom Anderen erwies es sich in der älteren und jüngeren Vergangenheit immer wieder als besonders hilfreich, die Gesellschaft jenseits der Scheidelinie als zivilisatorisch unterlegen, ja als barbarisch vorzustellen. Dieses Konzept ist auch in der Forschung aufgegriffen worden, am deutlichsten durch den amerikanischen Historiker Frederick Jackson Turners in seiner berühmten Abhandlung über The Significance of the Frontier in American History aus dem Jahre 1893, von der behauptet worden ist, sie sei, the most influential paper ever presented before a congress of Historians". 36

\section{Zivilisations- und Erschließungsgrenzen}

Es soll uns nicht darum gehen, einmal mehr ausgiebig die Turnersche Frontier-These zu erörtern, auch wenn sie zu Recht vor kurzem unter die großen Mythen der Geschichte aufgenommen worden ist. ${ }^{37}$ Doch soll sie nicht unerwähnt bleiben, weil sie sich für die Erforschung des Mittelalters als ungemein folgeträchtig erwiesen hat. Turner sah als prägende Erfahrung der amerikanischen Geschichte die Erschließung unkultivierter und unzivilisierter, sogar „,barbarischer“ Räume an, während der sich eine neue, eigene Gesellschaft auf der Grundlage eben dieser Grenzerfahrung gebildet habe. Viele Elemente dieses Konzepts haben einer kritischen Überprüfung nicht standgehalten, und dennoch wirkte es fort. ${ }^{38}$ Anfangs durchaus im Turnerschen Sinne der zivilisatorischen Erschließung auf die mittelalterliche Expansion - etwa des römisch-deutschen Reiches - übertragen, ist die Frontier-These nach dem Zweiten Weltkrieg vor allem auf die Iberische Halbinsel bezogen worden, wo ebenfalls die Grenze - die Glaubensgrenze - über die Zeit vorangeschoben wurde. ${ }^{39}$ Schnell wurde deutlich, daß bei den weitgehend urbanen, zivilisatorisch hochstehenden Gesellschaften in Al-Andalus die Vorstellung von der Barbarengrenze jeder Grundlage

in: Turiaso 7, 1987, 9-21; Fátima Roldán Castro, La frontera oriental nazarí (s. XIII-XVI). El concepto de alteridad a partir de las fuentes de la época, in: Segura Artero (Hrsg.), Actas del Congreso La Frontera Oriental Nazarí (wie Anm. 17), 563-570; Friedrich Edelmayer, Los de allá: imágenes y prejuicios sobre la frontera de los Austrias con el Imperio Otomano, in: Toro Ceballos / Rodríguez Molina (Hrsg.), IV Estudios de Frontera: Historia, tradiciones y leyendas (wie Anm. 23), 187-200.

36 Zitiert bei Peter Linehan, At the Spanish frontier, in: Peter Linehan; Janet L. Nelson (Hrsg.), The medieval world. London / New York / N. Y. 2001, 37-59, 37.

37 Manfred Berg, Der Mythos der Frontier und die amerikanische Identität, in: Helmut Altrichter / Klaus Herbers / Helmut Neuhaus (Hrsg.), Mythen in der Geschichte. (Rombach Wissenschaften. Reihe Historiae, Bd. 16.) Freiburg 2004, 519-540.

38 Richard W. Etulain, Does the frontier experience make America exceptional? Readings selected and introduced by Richard W. Etulain. Boston, Mass. [u.a.] 1999 und darin besonders: Martin Ridge, The life of an idea: the significance of Frederick Jackson Turner's frontier thesis, 73-86; Berg, Der Mythos der Frontier und die amerikanische Identität (wie Anm. 37).

39 Miguel Angel Ladero Quesada, Sobre la evolución de las fronteras medievales hispánicas (siglos XI a XIV), in: De Ayala Martínez / Buresi / Josserand (Hrsg.), Identidad y representación de la frontera (wie Anm. 13), 5-49. 
entbehrt. ${ }^{40}$ Charles Bishko, Robert Ignatius Burns, Angus MacKay und andere haben die militärische Expansion und die kolonisatorische Erschließung, haben also Reconquista und Repoblación unter diesem Vorzeichen neu auf der Grundlage Turners erörtert ${ }^{41}$, und in der Folge untersuchten auch spanische, portugiesische und französische Historiker die reichhaltigen Quellen der Iberischen Halbinsel auf diese Fragestellung hin. ${ }^{42}$ Gerade in den letzten Jahren dürften die mittelalterlichen Grenzen in keinem Land derart intensiv erforscht worden sein wie in Spanien. ${ }^{43}$ Dank dieser Arbeiten hat die Forschung zur Iberischen „Frontera" jede negative Konnotation eines zivilisatorischen Gefälles abgelegt und sich auch weitgehend vom Konzept der mit militärischen Mitteln vorangeschobene Erschließungsgrenze

40 Lawrence McCrank, Medieval Tarragona: A Frontier Town in New Catalonia, in: El Món urbà a la Corona d'Aragó del 1137 als Decrets de Nova Planta. (XVII Congrés d'Història d'Aragó, Barcelona-Lleida, 7-12- de setembre del 2000, Bd. 1.) Barcelona 2003, 441-474, 451-455; David S. H. Abulafia, Introduction: Seven Types of Ambiguity, c. 1100-c. 1500, in: Abulafia/ Berend (Hrsg.), Medieval Frontiers (wie Anm. 11), 1-34, 4.

41 Angus MacKay, Spain in the Middle Ages. From frontier to empire, 1000-1500. London 1977; Charles Julian Bishko, Studies in medieval Spanish frontier history. (Collected studies series, Bd. CS 124.) London 1980; Robert Bartlett / Angus MacKay (Hrsg.), Medieval frontier societies. Oxford 1989. Unter betonter Rückbindung an Turner: Robert I. Burns, King Alfonso and the Wild West: Medieval Hispanic Law on the U.S. Frontier, in: Medieval Encounters 6, 2000, 80100. Dieser Ansatz hat auch vergleichende Studien wie Robert Bartletts herausragende Synthese hervorgebracht: Robert Bartlett, The making of Europe: conquest, colonization, and cultural change, 950-1350. Princeton, N.J 1993, deutsch unter unglücklichem Titel: Die Geburt Europas aus dem Geist der Gewalt: Eroberung, Kolonisierung und kultureller Wandel von 950 bis 1350. München 1996.

42 Vgl. neben den Angaben in der folgenden Anm.: Manuel González Jiménez, Poblamiento y frontera en Andalucía (ss. XIII-XV), in: Espacio, Tiempo y Forma. Historia Medieval 1, 1988, 207-224; Ayala Martinez / Buresi / Josserand, Identidad y representación de la frontera en la España medieval (wie Anm. 13); programmatisch ist der Titel eines neueren Atlas: Jesús Mestre Campi / Flocel Sabaté, Atlas de la Reconquista: la frontera peninsular entre los siglos VIII y XV. Barcelona 1998. Unter den Beiträgen französischer Historiker sind herauszuheben: André Bazzana / Pierre Guichard/Philippe Sénac, La frontière dans l'Espagne médiévale, in: Poisson (Hrsg.), Frontière et peuplement (wie Anm. 32), 35-59; André Bazzana, El concepto de frontera en el Mediterráneo occidental en la Edad Media, in: Segura Artero (Hrsg.), Actas del Congreso La Frontera Oriental Nazarí (wie Anm. 17), 25-46; Philippe Sénac, La Frontière et les hommes (VIII $-\mathrm{XII}{ }^{\mathrm{e}}$ siècle). Le peuplement musulman au nord de l'Èbre et les débuts de la reconquête aragonaise. Paris 2000; Pascal Buresi, La frontière entre Chrétienté et islam dans la Péninsule ibérique. Du Tage à la Sierra Morena. Paris 2005.

43 Eine breite und dennoch unvollständige Übersicht der lebendigen Forschung liefert die 1993 zusammengestellte Bibliographie zum Sammelband: Las sociedades de frontera en la España medieval. (Seminario de Historia Medieval, Bd. 2.) Zaragoza 1993, 125-187, die durch die Beiträge und Literaturangaben einschlägiger jüngerer Sammelbände zu ergänzen sind: Segura Artero (Hrsg.), Actas del Congreso La Frontera Oriental Nazarí (wie Anm. 17); Pedro Luis Huerta Huerta (Hrsg.), Actas del IV Curso de Cultura Medieval: La fortificación medieval en la Península Ibérica, Centro de Estudios del Románico, Aguilar de Campoo, 21-26 de septiembre de 1992. Aguilar de Campoo 2001; Toro Ceballos / Rodríguez Molina (Hrsg.), Funciones de la red castral fronteriza (wie Anm. 1). 
verabschiedet, dem häufig ein gewisser Determinismus und die Suggestion einer Regelhaftigkeit zueigen ist. Dies bedeutet jedoch keineswegs, daß die militärische Dimension der mittelalterlichen Grenze negiert wird, im Gegenteil: Jüngere Arbeiten sind den iberischen Grenzbefestigungen und den Formen des Grenzkriegs gewidmet worden ${ }^{44}$, andere der Siedlungsgeschichte im Grenzraum. ${ }^{45}$ Hierbei ist der dynamischen spanischen Mittelalterarchäologie eine wichtige Funktion zugefallen.

In Ostmitteleuropa wurde lange unter politischen Vorzeichen um ein dem Turnerschen Modell vergleichbares Konzept eines kulturellen und allgemein entwicklungsgeschichtlichen Niveauunterschieds zwischen nicht-slawischer und slawischer Welt gerungen und gestritten. ${ }^{46}$ Vor allem die Forschung zur sogenannten Deutschen Ostsiedlung stand oftmals unter diesem Vorzeichen. Inzwischen hat die Diskussion merklich an Virulenz abgenommen; eine neue Geschichte der Siedlung in Mittel- und Ostmitteleuropa wird zu Recht in größere, europäische Zusammenhänge gestellt. ${ }^{47}$

44 So zuletzt - neben den in der vorangegangenen Fußnote genannten Titeln - in den Sammelbänden (mit weiterführender Literatur) Juan Antonio Barrio Barrio / José Vicente Cabezuelo Pliego (Hrsg.), La fortaleza medieval: realidad y símbolo. Murcia 1998; Isabel Cristina Ferreira Fernandes (Hrsg.), Mil anos de fortificaçoes na Península Ibérica e no Magreb (500-1500). Actas do Simpósio Internacional sobre Castelos. Lisboa 2002; Antonio Malpica, Los castillos en AlAndalus y la organización del territorio. Cáceres 2003. Zur Kriegsführung im Grenzraum: María Martinez Martinez, La cabalgada: un medio de vida en la frontera murciano-granadina (siglo XIII), in: Miscelánea Medieval Murciana 113, 1986, 51-62; Juan Carlos Docel Domínguez, La táctica de la batalla campal en la frontera de Granada durante el siglo XV, in: Segura Artero (Hrsg.), Actas del Congreso La Frontera Oriental Nazarí (wie Anm. 17), 137-144; Manuel González Jiménez, La caballería popular en la frontera, in: II Estudios de frontera: actividad y vida en la frontera (wie Anm. 1), 333-348; Emilio Martín Gutiérrez, Ordenanzas jerezanas del siglo XV sobre la milicia concejil y la frontera de Granada, in: Historia. Instituciones. Documentos 28, 2001, 377-390; Francisco Garcia Fitz, Una frontera caliente: la guerra en las fronteras castellano-musulmanas (siglos XI-XIII), in: De Ayala Martínez / Buresi / Josserand (Hrsg.), Identidad y representación de la frontera (wie Anm. 13), 159-179; Manuel Rojas Gabriel, El valor bélico de la cabalgada en la frontera de Granada (c. 1350-c. 1481), in: Anuario de estudios medievales 31, 2001, 295-328.

45 Vgl. den Beitrag und die Literaturangaben von José Angel García de Cortazar y Ruiz Aguirre in diesem Band.

46 Vgl. neben den Titeln in Anm. 29: Jan M. Piskorski, 1000 Jahre der deutsch-polnischen Grenze, in: Jahrbuch für die Geschichte Mittel- und Ostdeutschlands 44, 1996, 129-150; Eduard Mühle, Ostforschung und Nationalsozialismus. Kritische Bemerkungen zu einer aktuellen Forschungsdiskussion, in: Zeitschrift für Ostmitteleuropaforschung 50, 2001, 256-275.

47 Peter Erlen, Europäischer Landesausbau und mittelalterliche deutsche Ostsiedlung: ein struktureller Vergleich zwischen Südwestfrankreich, den Niederlanden und dem Ordensland Preußen. (Historische und landeskundliche Ostmitteleuropa-Studien, Bd. 9.) Marburg / Lahn 1992; Klaus Zernack, "Ostkolonisation" in universalgeschichtlicher Perspektive, in: Gangolf Hübinger / Jürgen Osterhammel/ Erich Pelzer (Hrsg.), Universalgeschichte und Nationalgeschichten. Festschrift für Ernst Schulin. Freiburg/Br. 1994, 105-116; Adrienne Körmendy, Melioratio terrae. Vergleichende Untersuchungen über die Siedlungsbewegung im östlichen Mitteleuropa im 13.14. Jahrhundert. Poznań 1995; vgl. auch die Beiträge von Christian Lübke, Jan M. Piskorski und Andreas Rüther in diesem Band. 
Doch lebt die Fragestellung der zivilisatorischen Erschließungsgrenze fort, indem sie sich mittlerweile auf benachbarte, weiter nördlich und südöstlich gelegene Gebiete verlagert hat. Hier, im baltisch-skandinavischen und im ungarischen Raum, kommt der Turnersche Entwurf in modifizierter Form zu neuer Anwendung. Das Konzept einer gegen alle Naturgewalten voranzutreibenden Erschließungsgrenze, aber auch das einer politischmilitärischen, mit Waffengewalt zu behauptenden oder zu verschiebenden Zivilisationsgrenze hat damit auch im Norden und Osten Europas große Zugkraft entfaltet. ${ }^{48}$

\section{Die Grenze als Kontaktbereich}

Auch die anonyme Gestalt auf dem Schäufeleinschen Holzschnitt trägt ein Schwert. Doch sie verteidigt keineswegs den Fluß, im Gegenteil: sie überschreitet ihn auf einer Brücke und wird damit zum „Grenzgänger" ${ }^{49}$ Ihr dient die Grenze als Übergang von einem Ort zum anderen, als Kontaktbereich. Diese Eigenschaft ist vielen Grenzgebieten eigen, was gerade in letzter Zeit in der Forschung besonders betont worden ist. Dies ist kein Zufall. Auch auf neuere Forschungsansätze wirken aktuelle Bezüge und Wünsche ein. Man könnte etwas überspitzt formulieren, daß dem Konzept des „Clash of Civilisations“, für das die Erforschung des militärischen und politischen Charakters der Grenze nutzbar gemacht worden ist, die Auffassung der Grenze als interkulturelle Nahtstelle des Mittelalters entgegengesetzt worden sei. Damit fügt sich die Ausrichtung innerhalb der Grenzforschung, die weniger nach dem trennenden als dem einenden Charakter historischer Grenzen fragt, in eine allgemeine Tendenz gerade der mitteleuropäischen Mediävistik ein, eine Tendenz zur Har-

48 Exemplarisch für den Stand der Forschung sind einige Beiträge in: Nils Blomkvist (Hrsg.), Europeans or not?: local level strategies on the Baltic Rim 1100-1400 AD; transactions of the Local Level Symposium of the Culture Clash or Compromise (CCC) Project, held in Kalmar May 7-10 1998. (CCC papers, Bd. 1.) Visby 1999; Jörn Staecker (Hrsg.), The European Frontier: Clashes and Compromises in the Middle Ages. (Lund studies in medieval archaeology, Bd. 33.) Lund 2004, besonders Jussi-Pekka Taavitsainen, Culture Clash or Compromise? The Notion of Boundary in the Utilization of Wilderness Areas, 45-57; reflektierend: Alan V. Murray (Hrsg.), Crusade and conversion on the Baltic frontier, 1150-1500: [International Medieval Congress, Leeds, 13-16 July, 1998]. Aldershot [u.a.] 2001, besonders William Urban, The Frontier Thesis and the Baltic Crusade, 45-71; Nils Blomkvist, The discovery of the Baltic: the reception of a Catholic world-system in the European north (AD 1075-1225). (The Northern World, Bd. 15.) Leiden [u.a.] 2005. Vgl. die für 2006 angekündigten Tagungsakten: Outi Merisalo (Hrsg.), Frontiers in the Middle Ages: Proceedings of the Third European Congress of Medieval Studies (Jyväskylä, 10-14 June 2003). (Textes et études du Moyen Âge, Bd. 35.) Turnhout 2006.

49 Monika Fludernik / Hans-Joachim Gehrke (Hrsg.), Grenzgänger zwischen Kulturen. (Identitäten und Alteritäten, Bd. 1.) Würzburg 1999; mit neuerer Literatur: Nikolas Jaspert, Eigenes und Fremdes im Spätmittelalter: Die deutsch-spanische Perspektive, in: Klaus Herbers / Nikolas Jaspert (Hrsg.), ,Das kommt mir Spanisch vor“. Eigenes und Fremdes in den deutsch-spanischen Beziehungen des späten Mittelalters. (Geschichte und Kultur der Iberischen Welt, Bd. 1.) Münster-Berlin 2004, 31-61. 
monisierung historischer Lebenswelten und Prozesse. ${ }^{50}$ Forschungsansätze wie die Kommunikationsforschung, Studien zu Konfliktregelung, Konfliktbeilegung und Symbolik sind nicht selten einer auf Ausgleich und ein friedliches Beieinander bedachten Weltsicht verpflichtet.

Auch wenn diese Vorstellung in jüngerer Zeit an Attraktivität gewonnen hat, neu ist sie nicht. Schon Jakob Grimm unterstrich in seiner bahnbrechenden Abhandlung über Deutsche Grenzalterthümer im Jahre 1843, die Grenze müsse ,nicht blosz als trennendes, sondern zugleich als einigendes princip behandelt werden, aus welchen neben der nothwendigen scheide ein band der nachbarschaft und gemeinschaft sich entfalte ${ }^{\text {c5l }}$ Seine Aufforderung ist lange von der Forschung nicht aufgegriffen worden und geriet zwischenzeitlich sogar in Vergessenheit. Erst in jüngerer Zeit beginnt man, sie ernsthaft umzusetzen. Noch 150 Jahre nach Grimms Studie hat Nora Berend mahnend mit den Worten daran erinnert „Frontiers have two sides, and societies on both are part of the picture“. ${ }^{52}$ Zwar birgt die Untersuchung grenzüberschreitender Kontakte stets die Gefahr, diesen allzu große Bedeutung beizumessen und zu übersehen, daß interkulturelle Beziehungen in Grenzgesellschaften häufig durch eine auffällige „Ideologie des Schweigens“ charakterisiert sind, daß also bestenfalls Pragmatismus das Verhältnis bestimmte, häufiger jedoch das Andere mit Nichterwähnung übergangen wurde. ${ }^{53}$ Doch bleibt festzuhalten, daß selbst die umkämpfteste Glaubensgrenze durch lange Perioden des Friedens gekennzeichnet war ${ }^{54}$, und jüngere Untersuchungen haben gezeigt, daß manche bislang als hermetisch angesehene Scheidelinie Durchlässigkeit aufwies. Dies gilt auch für Herrschaften an der Peripherie Europas, wie etwa die Kreuzfahrerstaaten des Vorderen Orients; ${ }^{55}$ vor allem aber trifft dies für die iberische Glaubensgrenze zu, denn ,,medieval Spain's frontier was probably permeable from the outset. It was certainly accostumed to twofold traffic ever after", wie Peter Linehan unlängst treffend formulierte. ${ }^{56}$ Diese vermeintliche Scheidelinie zwischen Al-Andalus und den christlichen Bereichen wurde von Menschen, Wissen und Waren sehr wohl überquert

50 Als südamerikanisches Beispiel: Angel Castellán, El concepto de la frontera (Para una metodología del encuentro de civilisaciones), in: Universidad de Buenos Aires. Facultad de Filosofía y Letras (Hrsg.), La frontera. Buenos Aires 1981, 7-25.

51 Jakob Grimm, Deutsche Grenzalterthümer (1843), in: Jakob Grimm (Hrsg.), Kleine Schriften II. Berlin 1865, 30-74, 31.

52 Berend, Medievalists and the Notion of the Frontier (wie Anm. 9), 64.

53 Charles J. Halperin, The Ideology of Silence: Prejudice and Pragmatism on the Medieval Religious Frontier, in: Comparative Studies in Society and History. An International Quarterly 26, 1984, 442-466: "silence, after all, is a powerful ideological tool" (ebd., 466).

$54 \mathrm{Zu}$ dieser Dichotomie Juan Torres Fontes, Dualidad fronteriza: guerra y paz, in: Segura Artero (Hrsg.), Actas del Congreso La Frontera Oriental Nazarí (wie Anm. 17), 63-78; María Jesús Viguera Molins, Guerra y paz en la frontera nazarí desde las fuentes árabes, ebd., 79-92.

55 Norman J. Housley, Frontier societies and the crusading movement in the late Middle Ages, in: Mediterranean historical review 10, 1995, 104-119; Ellenblum, Were there borders and borderlines in the Middle Ages (wie Anm. 11). Zu den Grenzen Europas und zum Begriff „Lateineuropa" siehe den Beitrag von Klaus Herbers in diesem Band.

56 Linehan, At the Spanish frontier (wie Anm. 36), 38; weiterhin ebd. 46, 54. 
und stellte viele Jahrhunderte lang eine interkulturelle Nahtstelle dar. ${ }^{57}$ Diese, aber auch andere Demarkationen waren nicht nur „Grenzen von Etwas“, sondern auch „Grenzen zwischen Etwas“ - und damit wesentliche Knotenpunkte der europäischen Verflechtungsgeschichte.

\section{Grenzraum und Grenzinstitution}

Grenzen als interkulturelle Nahtstellen zu verstehen, ist lediglich eine unter einer Reihe von Deutungen unseres Untersuchungsgegenstands, die den Cross-Cultural-Studies verpflichtet sind. Einer anderen liegt die Annahme zugrunde, bei der Grenze handele es sich weniger um eine Kontaktstelle als um einen Zwischenbereich, also um eine intermediäre Zone, eine „espace médian "58 oder - wie Richard White die „Frontier“ umbenannt sehen möchte -, ein „Middle Ground“. ${ }^{9}$ Diese Interpretation ist nicht zuletzt auch der Kulturlandschaftsforschung und der kulturlandschaftsgeographischen Grenzlandforschung verpflichtet. ${ }^{60}$ Damit wird dem Grenzraum ein eigener, deutlich vom Kernbereich einer Herrschaft abweichender Charakter bescheinigt. Solche mit eigenen Merkmalen versehene Übergangszonen können maritime $^{61}$, aber auch binnenländische Räume sein. Die geographische Entfernung vom jeweiligen Binnenreich, kommunikative Hemmnisse und die erwähnten grenzüberschrei-

57 Eduardo Manzano Moreno, Christian-Muslim frontier in al-Andalus: idea and reality, in: Dionisius A. Agius / Richard Hitchcock (Hrsg.), The Arab Influence in Medieval Europe: Folia Scholastica Mediterranea. (Middle East Cultures Series, Bd. 18.) Reading 1994, 83-99; ders., La organización fronteriza en al-Andalus durante la época omeya: Aspectos militares y sociales. Madrid 1999; ders., The Creation of a Medieval Frontier: Islam and Christianity in the Iberian Peninsula, Eighth to Eleventh Centuries, in: Power / Standen (Hrsg.), Frontiers in question (wie Anm. 10), 30-46; María Jesús Viguera Molíns, Las Fronteras de Al-Andalus, in: Toro Ceballos / Rodríguez Molina (Hrsg.), IV Estudios de Frontera: Historia, tradiciones y leyendas (wie Anm. 23), 593-610; Ann Christys, Crossing the Frontier of Ninth-Century Hispania, in: Abulafia / Berend (Hrsg.), Medieval frontiers (wie Anm. 11), 35-53.

58 Zumthor, La mesure du monde (wie Anm. 15), 234-257.

59 Zum Begriff des Middle Ground: Richard White, The middle ground: Indians, empires, and republics in the Great Lakes region, 1650-1815. Cambridge [u.a.] 1991; Christoph Marx, Grenzfälle. $\mathrm{Zu}$ Geschichte und Potential des Frontierbegriffs, in: Saeculum 54, 2003, 123-143, 124. Aus soziologischer und philosophischer Perspektive: Cremers, Relativität der Grenze - Grenzen der Relativität (wie Anm. 21), 7, 122-134.

60 Hierzu vgl. Irsigler, Der Einfluß politischer Grenzen auf die Siedlungs- und Kulturlandschaftsentwicklung (wie Anm. 13); Haubrichs / Schneider (Hrsg.), Grenzen und Grenzregionen (wie Anm. 30); Heller, Politische Grenzen und Grenzziehungen (wie Anm. 30), 176-179.

61 Vgl. die Beiträge im Abschnitt „La Frontera Marítima“ bei: Segura Artero (Hrsg.), Actas del Congreso La Frontera Oriental Nazarí (wie Anm. 17), 391-484; Manuel Flores Díaz, La concepción del mar como frontera en los textos jurídicos del siglo XIII en las coronas de Castilla y Aragón, in: II Estudios de frontera (wie Anm. 1), 245-255; Carlos Gonzalbes Cravioto, La frontera marítima del occidente malagueño en los documentos geográficos medievales cristianos, in: Toro Ceballos / Rodríguez Molina (Hrsg.), IV Estudios de Frontera: Historia, tradiciones y leyendas (wie Anm. 23), 247-266; Latorre Rodriguez, El agua como frontera (wie Anm. 23). 
tenden Kontakte führten unter Umständen zur Herausbildung eines eigenen Selbstverständnisses, aber auch eigener Wirtschaftsformen und politischer Strukturen. ${ }^{62}$

Allerdings hat zu recht kürzlich Jose Angel García de Cortázar eingefordert, daß die Eigenheiten der Peripherie nur dann postuliert werden können, wenn vorab das Wesen des Zentrums bestimmt worden ist. ${ }^{63}$ Dies ist nicht immer der Fall. Genauso wichtig ist es, die Kommunikationsmöglichkeiten zwischen beiden Bereichen in den Blick zu nehmen, um zu überprüfen, ob die Peripherie noch in Beziehung zum Zentrum steht und damit mit Fug und Recht als solche bezeichnet werden kann. ${ }^{64}$ Auch dies geschieht zu selten. Welche Probleme sich bei der Definition von Zentrum und Peripherie unseres Kontinents auftun, ist in letzter Zeit eingehend untersucht worden ${ }^{65}$, und daß die Binnengrenzen eines politischen Territoriums mitunter bedeutender sein konnten als Außengrenzen, ist etwa für Al-Andalus von Eduardo Manzano belegt worden. ${ }^{66}$

Trotz dieser Einschränkungen kann man festhalten: An der südwesteuropäischen und ostmitteleuropäischen Peripherie Lateineuropas entwickelten sich in der Tat Grenzräume, die eigene, spezifische Institutionen hervorbrachten. Die Grenzsituation konnte zum Beispiel vermittelnde Instanzen bedingen, die zur Konfliktregelung beitrugen. Auf der Iberischen Halbinsel etwa bemühten sich an der andalusischen Grenze im Spätmittelalter sogenannte ,jueces" oder ,alcaldes de la frontera“, bzw. „rastreros" und ,alcaldes entre los cristianos y moros" darum, Grenzstreitigkeiten im Verbund mit muslimischen Dienstleuten zu klären, um zu verhindern, daß den Territorien aus dem Nebeneinander unterschiedlicher Rechtsräume Nachteile entstanden. Eine Reihe von eigenen Rechtsinstitutionen kennzeichnete das Leben an der Grenze. ${ }^{67}$ In Ostmitteleuropa existierten ebenfalls Institutionen zur

62 Manuel Ruzafa García, Valencia, Castilla y Granada: una frontera económica bajomedieval, in: II Estudios de frontera (wie Anm. 1), 719-726; José Hinojosa Montalvo, El comercio y la frontera en la Península Ibérica en los siglos medievales, ebd., 385-413; Franz Irsigler, Grenzen und Wirtschaftsentwicklung in Mittelalter und früher Neuzeit. Eine Skizze, in: Schneider (Hrsg.), Natürliche und politische Grenzen (wie Anm. 23), 29-42.

63 José Angel García de Cortazar, De una sociedad de frontera (el Valle del Duero en el siglo X) a una frontera entre sociedades (el Valle del Tajo en el siglo XII), in: Las sociedades de frontera (wie Anm. 43), 51-68, 52 f.; Bazzana, El concepto de frontera (wie Anm. 42), 31.

64 Power/Standen, Introduction (wie Anm. 10), 22-25. Vgl. die Überlegungen unten bei Eduardo Manzano Moreno über die periphere Stellung, die Al-Andalus innerhalb des Dar al-Islam einnahm, sowie für das christliche Portugal den Beitrag von Umberto Baquero Moreno in diesem Band.

65 Klaus Herbers, Peripherie oder Zentrum? Spanien zwischen Europa und Afrika, in: Rainer Christoph Schwinges / Christian Hesse / Peter Moraw (Hrsg.), Europa im späten Mittelalter: Politik Gesellschaft - Kultur. (Historische Zeitschrift. Beihefte, Bd. N. F., 40.) München 2006, 99-124; Michael Borgolte, Christen, Juden, Muselmanen: die Erben der Antike und der Aufstieg des Abendlandes 300 bis 1400 n. Chr. München 2006.

66 Manzano Moreno, La organización fronteriza en al-Andalus (wie Anm. 57); vgl. Viguera Molíns, Las fronteras de Al-Andalus (wie Anm. 57). Zur Bedeutung der Binnengrenzen gegenüber den Außengrenzen vgl., mit weiterführender Literatur: Irsigler, Der Einfluß politischer Grenzen auf die Siedlungs- und Kulturlandschaftsentwicklung (wie Anm. 13), 18-22.

67 Angus MacKay, The ballad and the frontier in late medieval Spain, in: Bulletin of Hispanic studies 53, 1976, 15-33, 23-25; Angus MacKay, Los romances fronterizos como fuente histórica, in: 
Konfliktregelung, und in den Kreuzfahrerstaaten des Vorderen Orients wiederum ist an der Grenze das condominium durch Christen und Muslime über Liegenschaften im Grenzraum belegt. $^{68}$

In diesen Zusammenhang gehören auch militärische Institutionen, die im Grenzsaum geschaffen wurden. Europa brachte an seinen Grenzen - und nur an seinen Grenzen - miteinander verwandte Institute hervor, die als militärische Antwort auf die spezifischen Herausforderungen eines nicht nur kulturellen und politischen, sondern auch religiösen Antagonismus' entstanden. Die wichtigste dieser Institutionen waren die Ritterorden. An den drei wichtigsten Kontaktzonen zwischen Christentum und anderen Religionen entstanden bekanntlich eigene Kampfinstitute: Die Kreuzfahrerstaaten brachten die Templer, Johanniter, den Deutschen Orden, die Lazariten und den Thomasorden hervor; die Iberische Halbinsel den Calatrava-, Santiago- und Alcántaraorden nebst kleineren Gründungen wie die Orden von Teruel, Montesa, Montegaudio und Evora/Avis; und das Baltikum schließlich den Orden von Dobrin und die Schwertbrüder. Diese Ritterorden bieten sich bestens zum Vergleich zwischen den Grenzzonen Ostmittel- und Südwesteuropas an, was jedoch an dieser Stelle nicht in der gebotenen Präzision geleistet werden kann. Einige Hinweise mögen ausreichen, um die strukturellen und funktionalen Ähnlichkeiten dieser Institute in den beiden untersuchten Großräumen aufzuzeigen. ${ }^{69}$

Cristina Segura Graíño (Hrsg.), Relaciones exteriores del Reino de Granada. IV Coloquio de Historia Medieval Andaluza. Almería 1988, 273-283; José Enrique López de Coca Castañer, Institutions on the Castilian-Granadan frontier 1369-1482, in: Robert Bartlett; Angus I. K. MacKay (Hrsg.), Medieval frontier societies. Oxford 1989, 127-150, vgl. auch Pedro Andrés Porras Arboledas, El Derecho de Frontera durante la Baja Edad Media. La regulación de las relaciones fronterizas en tiempo de treguas y de guerra, in: Estudios dedicados a la memoria del Profesor L. M. Díez de Salazar., Bd. 1.) Bilbao 1992, 261-287; José Rodríguez Molina, relaciones pacíficas en la frontera con el reino de Granada, in: Segura Artero (Hrsg.), Actas del Congreso La Frontera Oriental Nazarí (wie Anm. 17), 257-290, 285-290; Viguera Molins, Guerra y paz en la frontera nazarí (wie Anm. 54), 84-86; Alfonso Carmona González, La frontera: doctrina islámica e instituciones nazaríes, ebd., 47-57, 56-57; Ahmed Benremdane, Notas sobre la frontera, la tolerancia y la convivencia cristiano-musulamanas y otras cuestiones de la vida diaria andalusí a través de los dictámenes jurídicos o "fatuas"” del alfaquí Al Uansarisi (1431-1508), in: II Estudios de frontera. Actividad y vida (wie Anm. 1), 113-124; Milouda Charouiti Hasnoui, La vida en la frontera granadino-castellana según las fetwas de ibn Tarkat y al-Wansarisi, ebd., 217-229; José Rodriguez Molina, Contratos de vecindad en la frontera de Granada, in: Revista del Centro de Estudios Históricos de Granada y su Reino 12, 1998, 33-56; Juan Luis Espejo Lara, Cautivos y alfaqueques en la frontera granadina: Antequera (1486), in: Revista de Estudios Antequeranos, 1994, 371-382.

68 Reinhard Schneider, Institutionen zur Regelung von Grenzkonflikten im Mittelalter, in: Granice i pogranicza - jezyk i historia, Warszawa 1994, S. 113-132; Ellenblum, Were there borders and borderlines in the Middle Ages (wie Anm. 11).

69 Vgl. hierzu auch die Beiträge und Literaturangaben von José Angel García de Cortazar y Ruiz Aguirre, Pascual Martínez Sopena und José Luis Martín Martín in diesem Band 
$\mathrm{Daß}$ die Ritterorden unmittelbar mit der Grenze verbunden und dieser gedanklich zugeordnet waren, zeigt jede Kartierung ihrer frühen Liegenschaften ${ }^{70}$, und daß sie nicht allein die regionale Antwort auf eine unmittelbare Herausforderung darstellten, sondern grundsätzlich als Institute des Grenzkampfs angesehen wurden, zeigt auch die Tatsache, daß sie auch fern von ihren Ursprungsorten zum Einsatz kamen: Templer, Johanniter und vielleicht auch Deutschordensritter kämpften auf der Iberischen Halbinsel, spanische Ritterorden sollten im Baltikum bzw. im Vorderen Orient aktiv werden, der Deutsche Orden fand ein neues Betätigungsfeld an der Ostsee, fern von seinem Entstehungsort. ${ }^{71}$

Im Gegensatz zum europäischen Binnenland, wo Ritterorden bekanntlich ebenfalls über Besitzungen verfügten, sich in ihrem Wirken aber nicht grundsätzlich von anderen religiosen Einrichtungen unterschieden, erfüllten sie an der Grenze ganz spezifische Aufgaben. Zum einen trugen sie durch die Errichtung bzw. Bemannung von Burgen und ihre Teilnahme an Heerzügen zur Verteidigung bzw. zur Verschiebung der Glaubensgrenze bei. ${ }^{72}$ Die spanische Reconquista bzw. die Unterwerfung heidnischer Stämme im Ostseeraum wäre ohne die militärische Beteiligung der Ritterorden mit Sicherheit bedeutend anders verlaufen oder sogar überhaupt nicht erfolgt. Zum anderen trugen die Ritterorden ebenfalls in Ost und West durch siedlungsaktivierende Maßnahmen unmittelbar zur Erschließung der Grenzräume bei und wirkten damit als Kolonisatoren erster Ordnung. ${ }^{73}$ In dieser Hinsicht ähnelte

70 Enrique Rodríguez-Picavea Matilla, La Orden de Calatrava en la meseta meridional castellana: encomiendas y distribución geográfica de las propiedades (1158-1212), in: Hispania: Revista española de historia 51, 1992, 875-899; Enrique Rodríguez-Picavea Matilla, Frontera, soberanía territorial y Órdenes Militares en la Península Ibérica durante la Edad Media, in: Hispania: Revista española de historia 52, 1992, 789-809; Enrique Rodriguez-Picavea Matilla, Las órdenes militares y la frontera. La contribución de las Órdenes a la jurisdicción territorial de Castilla en el siglo XII. (Encomienda. Serie Estudios, Bd. 1.) Madrid 1994; Nikolas Jaspert, Bonds and Tensions on the Frontier: The Templars in Twelfth-Century Western Catalonia, in: Jürgen Sarnowsky (Hrsg.), Mendicants, Military Orders and Regionalism in Medieval Europe. Aldershot 1999, 19-45; Carlos Barquero Goñi, Los Hospitalarios en la frontera de Granada entre los siglos XIII y XV, in: III Estudios de frontera (wie Anm. 15), 119-131.

71 Genannt seien lediglich einige jüngere Gesamtdarstellungen: Jesús Manuel Molero García, Participación del Orden del Hospital en el avance de la frontera castellana (1144-1224), in: Alar$\cos 1195=$ al-Arak 592 (Actas del Congreso Internacional Conmemorativo del VIII Cenetenario de la Batalla de Alarcos. Ciudad Real, 1995). Cuenca 1996, 331-351; Carlos de Ayala Martínez, Órdenes militares y frontera en la Castilla del siglo XIV, in: En la España medieval 23, 2000, 265-291; ders., Las órdenes militares castellano-leonesas y la acción de frontera en el siglo XIII, in: De Ayala Martínez / Buresi / Josserand (Hrsg.), Identidad y representación de la frontera (wie Anm. 13), 123-157; Ders, Las Órdenes Militares hispánicas en la Edad Media: siglos XII-XV. Madrid 2003; Philippe Josserand, Église et pouvoir dans la péninsule ibérique: les ordres militaires dans le royaume de Castille (1252-1369). (Bibliothèque de la Casa de Velázquez, Bd. 31.) Madrid 2004.

72 Einen Überblick zu der überbordenden Forschung vermittelt (mit Literaturangaben und ausführlicher Bibliographie): Zsolt Hunyadi (Hrsg.), The crusades and the military orders. Expanding the frontiers of medieval Latin christianity. Budapest 2001.

73 Die unterschiedlichen Funktionen der Ritterorden in Südwest- und Ostmitteleuropa sollen unter komparatistischer Perspektive an anderer Stelle erörtert werden. Vgl. bis dahin: Francisco Ruiz 
ihr Wirken dem der Zisterzienser, die bereits verschiedentlich als „,medieval frontiersmen“ gewürdigt worden sind. ${ }^{74}$ Nicht zuletzt ist auch die wirtschaftliche Bedeutung der Ritterorden hervorzuheben, die sich auf der Iberischen Halbinsel besonders im Bereich der Viehzucht niederschlug und in Ostmitteleuropa auch auf den Handel erstreckte. ${ }^{75}$

\section{Grenzgesellschaften}

Institutionen der Grenzräume wie etwa die Ritterorden sind nicht von den Gesellschaften, aus denen sie erwuchsen, zu trennen. Mithin gilt es auch, die gesellschaftlichen Auswirkungen der Grenzerfahrung zu beschreiben, die sozialen Folgen, welche die Präsenz oder die Nähe des Anderen, Fremden auf die Bevölkerung der Grenzzonen besaß. Hier stellt sich die Frage, ob die Peripherie eine eigene, spezifische Mentalität entwickelte. ${ }^{76}$ Bei der Erforschung der „Frontier societies“ wurde traditionell den Folgen dauerhafter militärischer Auseinandersetzungen und den besonderen Lebensbedingungen im Grenzsaum besondere Aufmerksamkeit gewidmet, vielleicht als Reflex des Turnerschen Grenzkonzepts. In der Tat bedurfte es attraktiver rechtlicher Anreize, um Menschen in den Grenzraum zu lok$\operatorname{ken}^{77}$, und besonderer politisch-militärischer Selbständigkeit, um dort zu bestehen. Diese konkreten lebensweltlichen Bedingungen hätten auf der Iberischen Halbinsel eine eigene,

Gómez, Los orígenes de las Órdenes Militares y la repoblación de los territorios de La Mancha (1150-1250). Madrid 2003; Karl Kasiske, Die Siedlungstätigkeit des Deutschen Ordens im östlichen Preußen bis 1410. Königsberg 1934; Reinhard Wenskus, Der Deutsche Orden und die nichtdeutsche Bevölkerung des Preußenlandes mit besonderer Berücksichtigung der Siedlung, in: Schlesinger (Hrsg.), Die deutsche Ostsiedlung des Mittelalters als Problem der europäischen Geschichte (wie Anm. 29), 417-438; Marian Biskup / Gerard Labuda, Dzieje Zakonu Krzyżackiego w Prusach. Gospodarka - społeczeństwo - państwo - ideologia. Gdańsk 1986, 189-193, 288315; Erlen, Europäischer Landesausbau und mittelalterliche deutsche Ostsiedlung (wie Anm. 47), 62-75, 101-119, 158-185, 248-266; Klaus Conrad, Der deutsche Orden und sein Landesausbau in Preußen, in: Udo Arnold (Hrsg.), Deutscher Orden 1190-1990. Lüneburg 1997, 83-106.

74 Lawrence J. McCrank, The Cistercians of Poblet as Medieval Frontiersmen: an Historiographic Essay and Case Study, in: Estudios en Homenaje a Don Claudio Sánchez Albornoz en sus 90 años. (Anejos de Cuadernos de Historia de España, Bd. 2.) Buenos Aires 1983, 310-360; Winfried Schich (Hrsg.), Siedlung - Landschaft - Religion. Studien zur Geschichte der Zisterzienser und zur ländlichen und städtischen Siedlung in der „Germania Slavica“. (Bibliothek der Brandenburgischen und Preußischen Geschichte, Bd. 11.) Berlin 2003.

75 Marie-Claude Gerbet, Les Ordres Militaires et l'élevage dans l'Espagne médiévale, in: En la España medieval 5, 1986, 413-445; Enrique Rodríguez-Picavea Matilla, La ganadería en la economía de frontera. Una aproximación al caso de la meseta merional castellana en los siglos XIXIV, in: De Ayala Martínez / Buresi / Josserand (Hrsg.), Identidad y representación de la frontera (wie Anm. 13), 181-203; Francisco Ruiz Gómez, La economía ganadera y los dominios de las órdenes militares en La Mancha en el siglo XII, in: Luis Adao da Fonseca/Luis Carlos Amaral / María Fernanda Ferreira Santos (Hrsg.), Os Reinos Ibéricos na Idade Média. Livro de Homenagem ao Professor Doutor Humberto Carlos Baquero Moreno. Oporto 2003, Bd. 1, 415-424; Roman Czaja / Jürgen Sarnowsky (Hrsg.), Die Ritterorden in der europäischen Wirtschaft des Mittelalters. (Ordines militares, Bd. 12.) Torun 2003. 
neue Grenzgesellschaft, eben eine ,Society organized for war“78, mit charakteristischen Formen städtischen und wirtschaftlichen Zusammenlebens hervorgebracht. ${ }^{79}$ Nicht nur Großgruppen, auch die Biographien herausragender Individuen seien unmittelbar durch die Grenzerfahrung geprägt. Helden wie Rodrigo Díaz de Vivar - el Cid -, Arnau Mir de Tost, aber auch ostmitteleuropäische Pendants wie König Ladislaus von Ungarn etwa seien nur aus der Konfliktsituation der mittelalterlichen Glaubensgrenze heraus erklärbar. ${ }^{80}$ Der Konflikt habe also ganz spezifische soziale Gebilde bedingt. In der Tat formte nicht nur die Grenzerfahrung, sondern auch die über mehrere Jahrhunderte hinweg immer wieder geführten Auseinandersetzungen mit anderen Religionen die Geschichte, vor allem aber das Selbstverständnis der europäischen Peripherie, im Westen wie im Osten Europas. ${ }^{81}$ Um die

76 Zur Frontier als "State of mind": Abulafia, Introduction: Seven Types of Ambiguity (wie Anm. 40), 34.

77 Vgl. dazu José Angel García de Cortazar / Ana Maria Barrero Garcia, Los derechos de la frontera, in: Las sociedades de frontera (wie Anm. 43), 69-80; zur Siedlungsgeschichte vor dem Hintergrund der Grenzthematik siehe weiterhin Poisson (Hrsg.), Frontière et peuplement (wie Anm. 32) und Soto Rábanos, La frontera (wie Anm. 17). Vgl. hierzu die Beiträge und Literaturangaben von Andreas Rüther, Christian Lübke und Pascual Martínez Sopena in diesem Band.

78 Elena Lourie, A Society Organized for War: Medieval Spain, in: Past and Present 35, 1966, 5476; aufgegriffen von James F. Powers, A society organized for war: the Iberian municipal militias in the central middle ages, 1000-1284. Berkeley [u.a.] 1988.

79 Vgl. die Vielzahl an Publikationen, die den "sociedades de frontera" gewidmet sind: Las sociedades de frontera en la España medieval (wie Anm. 43); Maria Martínez Martínez, Organización y evolución de una sociedad de frontera: el reino de Murcia (ss. XIII-XV), in: Medievalismo: Boletín de la Sociedad Española de Estudios Medievales 5, 1995, 31-88; María Carmen Trillo San José, Una nueva sociedad, un nuevo paisaje. Los señoríos castellanos de la frontera nororiental del Reino de Granada, in: Aragón en la Edad Media 14-15, 1999, 1545-1564; Segura Graiño, Una reflexión sobre las fronteras en la Edad Media (wie Anm. 21); Carmen Diez Herre$r a$, La organización social del espacio entre la cordillera Cantábrica y el Duero en los siglos VIII al XI. Una propuesta de análisis como sociedad de frontera, in: José Angel García de Cortázar Ruiz de Aguirre (Hrsg.), Del Cantábrico al Duero: trece estudios sobre organización social del espacio en los siglos VIII a XIII. Universidad de Cantabria 1999, 123-156; María Martínez Martínez, Las mujeres en la organización de una sociedad de frontera: la etapa colonizadorarepobladora de Murcia, 1266-1272. Murcia 2000. Vgl. dazu auch die Beiträge und Literaturangaben von Humberto Baquero, Pascual Martínez Sopena, Christian Lübke und Andreas Rüther in diesem Band.

80 Nilda Guglielmi, Fronteras medievales, in: Universidad de Buenos Aires. Facultad de Filosofia y Letras (Hrsg.), La frontera. Buenos Aires 1981, 27-51; Miguel Angel Ladero Quesada, El héroe en la frontera de Granada, in: Cuadernos del CEMYR 1, 1993, 75-100. Zur Wirkung auf den Adel im allgemeinen: Rafael Sánchez Saus, Aristocracia y frontera en la Andalucía medieval, in: Estudios de historia y de arqueología medievales 11, 1996, 191-215; Jesús Molero, La frontera castellana en tiempos de Alfonso VII: nobleza y organización del espacio, in: II Estudios de frontera. Actividad y vida (wie Anm. 1), 585-601; Manuel Rojas Gabriel, La nobleza como élite militar en la frontera con Granada. Una reflexión, in: Segura Artero (Hrsg.), Actas del Congreso La Frontera Oriental Nazarí (wie Anm. 17), 181-190.

81 Grzegorz Mysliwski, Boundaries and Men in Poland from the twelfth to the sixteenth century: the case of Masovia, in: Abulafia / Berend (Hrsg.), Medieval frontiers (wie Anm. 11), 217-237. 
Grenze und an ihr entsponnen sich Legenden und eigene Kulte, wie insbesondere am iberischen Beispiel beobachtet worden ist. ${ }^{82}$ Die Iberischen Reiche und ihre Herrscher sahen sich ebenso als Vorkämpfer ihres Glaubens und Bollwerke gegen Andersgläubige (propugnacula fidei) wie ostmitteleuropäische Herrschaften und Fürsten. ${ }^{83}$

Doch die Herrschaften Europas waren weder sprachlich noch konfessionell oder kulturell so homogen, wie traditionell angenommen, dies haben jüngere Studien belegt, in denen auf die die Vielzahl unterschiedlichster Enklaven in den Grenzzonen hingewiesen wird. Denn nicht nur die militärische Auseinandersetzung, sondern auch der interkulturelle Kontakt zeitigte Folgen. Gerade das Voranschieben der Grenze führte dazu, daß Menschen unterschiedlicher Religionen und Kulturen in die Grenzgesellschaften integriert wurden; hier stellt sich die Frage, ob und wie Assimilations- und Akkulturationsprozesse bei den Unterworfenen stattfanden, welche Rückkopplungseffekte auf die dominierende Gesellschaft festzustellen sind. ${ }^{84}$ Derartige Prozesse sind oftmals schwer zu verfolgen, und auch die Namenforschung gerät hier schnell an ihre Grenzen. ${ }^{85}$ Akkulturation und Synkretismus in den Berührungszonen sind in verschiedenen Räumen beobachtet worden. Das gängige Bild der Gebiete südlich des Duerotals als einer wüsten, menschenfreien Grenzzone ist zuletzt revidiert worden; es habe sich bei solchen Räumen vielmehr um Gebiet religiöser und kultureller Mischgesellschaften gehandelt, die im übrigen wenig mit ihren jeweiligen Kerngebieten in Al-Andalus bzw. im christlichen Norden gemein hatten. ${ }^{86}$ Gebrochene und changierende Loyalitäten kennzeichnen folglich manche Grenzzonen, deren Ränder in jüngeren Darstellungen endgültig zu verschwimmen scheinen. Gerade weil die Herrschenden - seien es Christen oder Muslime - selten zum Mittel systematischer und vollständiger Vertreibung griffen und eigene Strategien im Umgang mit Andersgläubigen schufen, entwickelten sich hier vielfältig abgestufte Grenzgesellschaften, in denen Anhänger unter-

82 Vgl. die Beiträge in Toro Ceballos / Rodríguez Molina (Hrsg.), IV Estudios de Frontera: Historia, tradiciones y leyendas (wie Anm. 23). Jacek Banaszkiewicz, Fabularyzacja przestrzeni. Sredniowieczny przykład granic, in: Kwartalnik Historyczny 86, 1979, 987-999; ders., Polskie dzieje bajeczne mistrza Wincentego Kadłubka (Monografie Fundacji na Rzecz Nauki Polskiej), Wrocław ${ }^{2} 2002$, 349-453. Vgl. die Beiträge von Roman Michalowski und Patrick Henriet in diesem Band.

83 Knoll, Poland as "antemurale Christianitatis" in the Late Middle Ages (wie Anm. 35); Edelmayer, Los de allá (wie Anm. 35); Linehan, At the Spanish frontier (wie Anm. 36), 46; Berend, Hungary, "the gate of christendom", (wie Anm. 12); Housley, Frontier societies and the crusading movement in the late Middle Ages (wie Anm. 55), 109-110.

84 Enrique Rodriguez-Picavea Matilla, Un ejemplo de aculturación cristiano-feudal en la frontera nazari: la Orden de Calatrava en Alcaudete, in: Actas del II Congreso de Historia de Andalucía. Córdoba, 1991, Bd. 2. Córdoba 1994-1995, 49-81. Vgl. dazu auch die Beiträge und Literaturangaben von Christian Lübke, Matthias Maser, Jean-Pierre Molénat, Eduardo Manzano Moreno und Jan M. Piskorski in diesem Band.

85 Vgl. den Beitrag von Christiane Schiller in diesem Band.

86 Manzano Moreno, Christian-Muslim frontier in al-Andalus (wie Anm. 57); Despoblación y colonización del valle del Duero, siglos VIII-XX. (Fundación Sánchez-Albornoz, IV Congreso de Estudios Medievales) Ávila 1995. Daß die Grenzgebiete allerdings in der Tat nur schwach besiedelt gewesen sein dürften, sei betont. 
schiedlicher Religionen Jahrzehnte und Jahrhunderte lang Formen gemeinsamen Auskommens suchten und fanden. ${ }^{87}$ Ähnliche ethnische und religiöse Mischgesellschaften liegen auch in Ostmitteleuropa vor, wo nicht nur Heiden und unterschiedliche christliche Denominationen aufeinanderstießen, sondern - in Ungarn und Litauen etwa - auch muslimische Minderheiten existierten. ${ }^{88}$ Diese multireligiösen Grenzgesellschaften an den östlichen und westlichen Peripherien Europas waren während des Mittelalters zweifellos weniger hermetisch als in späterer Zeit. ${ }^{89} \mathrm{Daß}$ diese Territorien zugleich voller Ungleichheiten und sozialer Hierarchien waren, daß sie auch Zeiten gesteigerter Gewalt und Verfolgung kannten, sei hinzugefügt, um nicht das Wunschbild toleranter, multikonfessioneller und multiethnischer Kollektive aufkommen zu lassen; ${ }^{90}$ denn auch bei dieser Perspektive wird unschwer der aktuelle Hintergrund deutlich, drängt sich in Zeiten multikulturellen Zusammenlebens doch die Suche nach vergleichbaren Gesellschaften in der Vergangenheit leicht auf.

Die vielen Grenzkonzepte und Ausprägungen der Grenze, die ,tausend Gesichter der Grenze $^{691}$, verwirren - und erschweren jede wissenschaftliche Beschäftigung mit dem Thema. Sollte in dieser Aufsatzsammlung nun über ,Linien oder Säume, Zonen oder Räume ${ }^{c 92}$ geschrieben werden, über feste oder expandierende Scheidelinien, über Zonen zivilisatorischen Gefälles oder kulturellen Austauschs, über die Beziehungen zwischen Gesellschaften beiderseits der Grenze oder über diejenige innerhalb einer Grenzgesellschaft? Hier erweist es sich als heuristisches Hemmnis, daß die Forschung keine klare Terminologie entwickelt hat, um die unterschiedlichen Facetten der Grenzerfahrung zu kennzeichnen.

Ist dies allein ein Merkmal der jüngeren wissenschaftlichen Beschäftigung, oder war auch die mittelalterliche Begrifflichkeit bezüglich der Grenze alles andere als stringent? Dies ist keine Frage ausschließlich philologischen Interesses, denn die Betrachtung zeitgenössischer Termini kann nicht zuletzt davor bewahren, im Strudel der Interpretamente zu versinken oder sich in den manchmal nebulösen Gefilden der „Liminalität“ zu verlieren.

87 Housley, Frontier societies and the crusading movement in the late Middle Ages (wie Anm. 55); "At least until the fifteenth century, ethnic cleansing was not part of their policy": Linehan, At the Spanish frontier (wie Anm. 36), 49. Vgl. mit Literaturangaben: Rodríguez Molina, Relaciones pacíficas en la frontera (wie Anm. 67); ders., Libre determinación religiosa en la frontera de Granada, in: II Estudios de frontera. Actividad y vida (wie Anm. 1), 693-708; ders., Contactos pacíficos en la frontera de Granada, in: I Encuentro de Historia Medieval de Andalucía. Sevilla, 1998. Sevilla 1999, 19-43.

88 Vgl. die Beiträge und die Literaturangaben von Christian Lübke, Christiane Schiller und Nora Berend in diesem Band.

89 Vgl. die Worte von Jean-Pierre Molénat in diesem Band: "Au total, la 'frontière' est plus présente et infranchissable au XVI ${ }^{\mathrm{e}}$ siècle que jamais elle ne l'a été auparavant" (siehe unten, $\mathrm{S}$. 200).

90 Linehan, At the Spanish frontier (wie Anm. 36).

91 José L. Martín Martín, Las mil caras de la frontera, in: III Estudios de frontera (wie Anm. 15), 35-54.

92 Pohl, Soziale Grenzen und Spielräume der Macht (wie Anm. 25), 8. 


\section{Grenzbegriffe}

In der Tat entspricht die Fülle an Definitionen und Fragestellungen, die gegenwärtig mit dem Begriff der Grenze verbunden ist, der Vielzahl an Termini, mit denen im Mittelalter Scheidelinien und -zonen bezeichnet wurden. ${ }^{93}$ Allein in den zeitgenössischen lateinischen Quellen findet sich eine lange Reihe einschlägiger Begriffe: limes, marca, meta, gades, terminus, finis, confinium, frontera, signum. Von den volkssprachigen Bezeichnungen ganz zu schweigen, denen im deutschsprachigen Bereich die erwähnte Abhandlung Jakob Grimms galt. ${ }^{94}$ Es soll nicht Ziel sein, die Herkunft und Anwendung aller dieser Begriffe zu referieren. Doch auf drei von ihnen soll dennoch etwas genauer eingegangen werden, da sie innerhalb der Forschungsgeschichte eine besondere Rolle gespielt haben: auf die Bezeichnung ,Grenze“, „Mark" und „Frontera/Frontier“.

Grenze ist bekanntlich ein slawisches Lehnwort. ${ }^{95}$ Vom slawischen „granica“ ausgehend, fand es als granicea Ende des 12. Jahrhunderts seinen Weg ins Lateinische - zuerst im heutigen Polen, dann in Böhmen und Ungarn -, und ein halbes Jahrhundert später trifft man auf erste Belege für die Bezeichnung grenitze im Deutschen, auffälligerweise zuerst im Herrschaftsbereich des Deutschen Ordens und in zisterziensischen Quellen. Dort verdrängte es allmählich ältere Bezeichnungen wie Wegrein, Mark oder Landscheide. ${ }^{96}$ Vom Deutschen fand es ab dem 16. Jahrhundert Aufnahme in andere Sprachen wie das Niederländische. Dank der Arbeiten Hans-Jürgen Karps, Herbert Kolbs und Winfried Schichs wissen wir inzwischen, warum ein fremdes Wort benutzt wurde, um etwas zu beschreiben, das auf den ersten Blick schon lange existierte. Der Begriff granica umschrieb nämlich nicht irgendeine Trennlinie, sondern die innerhalb des Waldes mit Zeichen markierte Grenze; strenggenommen waren es sogar die auf Bäumen, vor allem Eichen angebrachten Zeichen, die diese Benennung erhielten. ${ }^{97}$ Diese im Gedanken zu einer Linie verbundenen

93 Eine Überblick zur Begrifflichkeit bieten: Winfried Schich, Die „Grenze“ im östlichen Mitteleuropa im hohen Mittelalter, in: Siedlungsforschung. Archäologie-Geschichte-Geographie 9, 1991, 135-145; Johannes Kramer, Bezeichnungen für „Grenze“ in den europäischen Sprachen, in: Diagonal 1993, 15-24; Max Pfister, Grenzbezeichnungen im Italoromanischen und Gallorromanischen, in: Haubrichs / Schneider (Hrsg.), Grenzen und Grenzregionen (wie Anm. 30), 37-48; Nicklis, Von der "Grenitze" zur Grenze (wie Anm. 7); Roland Marti, Grenzbezeichnungen grenzüberschreitend, in: Wolfgang Haubrichs / Kurt-Ulrich Jäschke / Michael Oberweis (Hrsg.), Grenzen erkennen - Begrenzungen überwinden. Festschrift für Reinhard Schneider zur Vollendung seines 65. Lebensjahrs. Sigmaringen 1999, 19-33.

94 Grimm, Deutsche Grenzalterthümer (1843) (wie Anm. 51); Irsigler, Der Einfluß politischer Grenzen auf die Siedlungs- und Kulturlandschaftsentwicklung (wie Anm. 13), 10.

95 Marti, Grenzbezeichnungen - grenzüberschreitend (wie Anm. 93); Kramer, Bezeichnungen für „Grenze“ in den europäischen Sprachen (wie Anm. 93), 22 f.

$96 \mathrm{Zu}$ älteren Flur- und Grenzbezeichnungen vgl. Bauer, Die ältesten Grenzbeschreibungen in Bayern (wie Anm. 6).

97 Karp, Grenzen in Ostmitteleuropa während des Mittelalters (wie Anm. 4); Herbert Kolb, Zur Frühgeschichte des Wortes "Grenze", in: Archiv für das Studium der neueren Sprachen und Lite- 
Markierungen, die „Grenze“, bildeten nicht den Rand eines gesicherten, durchdrungenen Raums, sondern die äußerste Linie einer noch zu integrierenden, herrschaftlich und administrativ zu verdichtenden Landschaft. ${ }^{98}$ Der Grenzbegriff ist also untrennbar mit planmäßigem Landesausbau und mit Siedlung verknüpft, er bezeichnet die künstlich durch Markierungen und durch zusätzliche rituelle Handlungen wie den Umgang oder Umritt abgesteckte Erschließungsgrenze.

Wenden wir uns dem Begriff der Mark zu: Er hat im Laufe seiner Geschichte einen starken Bedeutungswandel erlebt, wie Ruth Schmidt-Wiegand und andere dargelegt haben: ${ }^{99}$ Von der mutmaßlichen Urbedeutung ,Wald“ über die eines breiten, nur extensiv genutzten Grenzsaumes bis zur ,,abgemarkten“, durch Zeichen „,markierten“ Grenzlinie. ${ }^{100}$ Am bekanntesten ist der Gebrauch des Wortes marca aus der Karolinger- und Ottonenzeit, als mit diesem Begriff vorgelagerte Sicherungszonen benannt wurden, die allmählich in das Reich hineinwuchsen und ihrerseits neue Außengrenzen ausbildeten. ${ }^{101}$ Die lateinische marca ist damit dem slawischen „kraj“ vergleichbar, das noch heute ehemaligen Grenzgebieten wie der Ukraine, der Krajina oder Krain ebenso den Namen gibt, wie die marca bekanntlich in den walisischen Marches, den italienischen Marche und den deutschen Marken fortlebt.

Der Begriff der marca ist ein einprägsames Beispiel für die Politisierung der historischen Grenzforschung, denn er wurde verschiedentlich in der Historiographie und historischen Geographie dazu benutzt, aktuelle Herrschaftsansprüche historisch zu begründen. Man denke nur an die sogenannte Marca Hispanica. Der Begriff findet sich zwar in der Tat in den lateinischen Quellen der Karolingerzeit, doch bezeichnete er weder einen geschlossen, einem comites marcae unterstehenden Grenzsaum eines Reichs, noch ein einheitliches, mit eigenem Bewußtsein ausgestattetes Territorium. Diese beiden Interpretamente jedoch wurden über lange Zeit von der französischern und katalanischen Forschung vertreten. Der

raturen 226, 1989, 344-356; Schich, Die „Grenze“ im östlichen Mitteleuropa (wie Anm. 93); Nicklis, Von der "Grenitze" zur Grenze (wie Anm. 7). Am Beispiel Masowiens: Mysliwski, Boundaries and men in Poland (wie Anm. 81). Dies ist auch in weiter westlich gelegenen Gebieten belegt: Bauer, Die ältesten Grenzbeschreibungen in Bayern (wie Anm. 6), 45-46. Andere Beispiele für Grenzmarkierungen bei Lagazzi, Segni sulla terra (wie Anm. 5).

98 Marchal, Grenzerfahrung und Raumvorstellungen: Zur Thematik des Kolloquiums (wie Anm. 13), $17 \mathrm{f}$.

99 Kramer, Bezeichnungen für „Grenze“ in den europäischen Sprachen (wie Anm. 93), $21 \mathrm{f}$.

100 Ruth Schmidt-Wiegand: Marca. Zu den Begriffen „Mark“ und „Gemarkung“ in den Leges Barbarorum, in: Dies., Stammesrecht und Volkssprache. Ausgewählte Aufsätze zu den Leges barbarorum. Weinheim 1991, 335-352; Irsigler, Der Einfluß politischer Grenzen auf die Siedlungsund Kulturlandschaftsentwicklung (wie Anm. 13), 11-16. Zum Streit darum, ob die marca entvölkert oder doch besiedelt war: Michel Zimmermann, Le rôle de la frontière dans la formation de la Catalogne (IX-XIIème siècle), in: Las sociedades de frontera (wie Anm. 43), 7-29, 12-26; García de Cortazar, De una sociedad de frontera (wie Anm. 63), 54; McCrank, Medieval Tarragona: A Frontier Town in New Catalonia (wie Anm. 40), 451 erinnert daran, dass gleich nach der christlichen Eroberung Weinberge und Olivenhaine übergeben wurden, was auf ältere landwirtschaftliche Nutzung schließen läßt.

101 Vgl. Irsigler, Der Einfluß politischer Grenzen auf die Siedlungs- und Kulturlandschaftsentwikkung (wie Anm. 13), 11-15. 
einflußreiche Historiker, Prälat und Politiker Pierre de Marca benutzte den Begriff der Marca Hispanica bereits im 17. Jahrhundert dazu, die Ansprüche der französischen Krone auf pyrenäische Gebiete historisch zu legitimieren, und katalanische Historiker sahen allzu gerne in der Marca Hispanica ein bereits vollständig vorgebildetes, frühes Katalonien. ${ }^{102}$ In Wirklichkeit waren die comes marcae aber weitgehend unabhängig voneinander operierende Herrschaftsträger, und der Begriff der Mark bezeichnete im 9. Jahrhundert im iberischen Bereich keinen Raum, sondern eine Grenzlinie. ${ }^{103}$ Erst im ausgehenden 10. Jahrhundert erlangte der Begriff, nun jedoch im lokalen Kontext, den Bedeutungsgehalt eines Territoriums, und zwar eines Herrschaftsraums, der nicht unbedingt an der Grenze liegen mußte.

Unser dritter Terminus ist die in den gallo-romanischen Sprachen und im Englischen gebräuchliche Bezeichnung für Grenze: ,,frontera“, „frontière“, „frontier“. ${ }^{104}$ Der Begriff geht etymologisch auf das Lateinische frons, also die Stirn zurück, was bereits ausdrückt, daß er einem Grenzverständnis entspringt, welches stark aus der Gegnerschaft zum oder zumindest der Absetzung vom Anderen, jenseits der Grenze Befindlichen, erwächst. Der militärische Charakter des Begriffs ist allen gallo-romanischen Sprachen eigen ${ }^{105}$, doch am frühesten - seit dem 12. Jahrhundert ${ }^{106}$ - und am stringentesten wurde er auf der Iberischen Halbinsel verwendet. Dort weist die ,frontera“ zwei Merkmale auf. Zum einen ist sie weitaus deutlicher als die beiden anderen vorgestellten Termini als Religionsgrenze zu verstehen. ${ }^{107}$ Sie bezeichnet zumindest in den iberischen Quellen in der Regel das Grenzgebiet zum Islam. Zum anderen ist die ,frontera" nicht statisch, sondern bewegt sich im Raum je nach der militärischen Lage mal vorwärts, mal zurück - auch wenn sie auf lange Dauer und aus Sicht der Christen auf der Iberischen Halbinsel letztlich vorangeschoben wurde. Mit der Zeit benannte der Begriff zunehmend eine klar gezogene, auch befestigte Grenzlinie zwischen Gebieten mehrheitlich andersartiger Religionen. ${ }^{108}$

102 Brunet, Les Pyrénées: Genèse de la frontière (wie Anm. 26). Ein jüngerer, reflektierter Zugang: Zimmermann, Le rôle de la frontière (wie Anm. 100).

103 Ebd., 9-10 mit älterer Literatur.

104 Kramer, Bezeichnungen für „Grenze“ in den europäischen Sprachen (wie Anm. 93), 19 f.; Jean Pierre Molénat, Les diverses notions de ,frontière' dans la region de Castilla-La Mancha au temps des Almoravides et des Almohades, in: Alarcos $1195=$ al-Arak 592 (Actas del Congreso Internacional Conmemorativo del VIII Cenetenario de la Batalla de Alarcos. Ciudad Real, 1995.) Cuenca 1996, 105-123.

105 Febvre hat die Entwicklung des Wortes und seinen Bedeutungswandel untersucht: Lucien Febvre, „Frontière“ - Wort und Bedeutung, in: Ders., Das Gewissen des Historikers. Berlin 1988, 27-38.

106 Nora Berend, Preface, in: Abulafia / Berend (Hrsg.), Medieval frontiers (wie Anm. 11), X-XV, XII.

107 Jean Gautier Dalché, Islam et chrétienté en Espagne au XII ${ }^{\mathrm{e}}$ siècle: contribution à l'étude de la notion de frontière, in: Hespéris 46, 1959, 183-217; Philippe Senac, Islam et chrétienté dans l'Espagne du haut Moyen Âge: la naisssance d'une frontiére, in: Studia Islamica 89, 1999, 91108.

108 Gautier Dalché, Islam et chrétienté en Espagne au XII siècle (wie Anm. 107); Bazzana./ Guichard / Sénac, La frontière dans l’Espagne médiévale (wie Anm. 42); García de Cortazar, De una sociedad de frontera (wie Anm. 63); Maria Isabel Pérez de Tudela Velasco, El concepto de 
An dieser Stelle könnte man unsere Liste einschlägiger Termini um den arabischen Begriff des Tagr ergänzen, jenes weitgehend autonomen, in seiner geographischen Beschaffenheit variablen Grenzgebiets zwischen Islam und Christentum. ${ }^{109}$ Doch dürfte - und damit resümiere ich meine kurze Sprachbetrachtung - deutlich geworden sein, daß unterschiedliche Grenzkonzeptionen in der aktuellen Forschung keineswegs ein neuzeitliches Konstrukt sind, sondern beizeiten, wenn auch nicht immer, in den zeitgenössischen Quellen eine Bestätigung finden. Wenn Bezeichnungen wie marca sich aus dem Begriff für Wald ableiten, liegt ein vollkommen anderes, auf Abtrennung ausgerichtetes Konzept der Grenze vor als beim muslimischen Tagr, beim lateinischen limes - der auch Paß oder Pforte bedeuten konnte -, oder bei dem beide Seiten der Grenze bedenkenden Begriff des confinium. Diese Termini deuten stärker auf den Bereich der interkulturellen Kontakte. Und während granica, signum oder meta offenbar als markierte Scheidelinie gedacht wurde, unterstreichen Bezeichnungen wie terminus stärker die Binnenwirkung einer Außengrenze, indem sie die äußere Hülle eines Territoriums betonen. ${ }^{110}$ In Mittelalter ebenso wie in der Moderne war die Grenze stets ein komplexes, vielschichtiges Feld, das sich letztlich einer kohärenten Definition entzieht.

\section{Borders and border-areas in the Middle Ages: Research, concepts and definitions}

Using a 15 th century wood carving as a starting point and leitmotiv, this article aims at presenting an overview of both recent and medieval definitions and perceptions of borders, border zones and frontiers. It does so in seven steps, the first of which is dedicated to theological views and assessments of frontiers; it also treats the question, if contemporaries were in fact able to conceive straight border lines at all. A second chapter attempts to demonstrate that the concept of natural, geographic borders - albeit present in the medieval mind - has often been a highly political issue, a notion strongly tied to the dichotomy of "self" and "other". A brief overview of recent Iberian and East Central European research on the history of medieval borders shows that the subject has by no means lost its academic and popular attraction. The fourth part underlines that recent interpretations prefer to see frontiers as contact zones rather than as a divide, while the following pages lay less emphasis on border lines than on the area between territories, which modern research perceives as an ,espace médian“" or a „Middle Ground“" particularly prone to bringing forth specific institutions. The medieval

frontera en la historiografia medieval hispana, in: Castellum 2, 1996, 131-140. Zur Spätgeschichte des Begriffs siehe die einschlägigen Seiten bei Fernand Braudel, Raum und Geschichte. Frankfurt am Main [u.a.] 1989, 316-380.

109 Vgl. García de Cortazar, De una sociedad de frontera (wie Anm. 63), 53 mit Literatur; Pedro Chalmeta Gendrón, El concepto de tagr, in: Philippe Sénac (Hrsg.), La Marche supérieure d'alAndalus et l'Occident chrétien. (Publications de la Casa de Velázquez. Série archéologie, Bd. 15.) Madrid 1991, 15-27; Eduardo Manzano Moreno, La projecció de l'estat omeia al Tagr, in: Manuel Pedro Acién Almansa u.a. (Hrsg.), L’Islam i Catalunya. Barcelona 1998, 65-69.

110 Vgl. Hierzu Power / Standen, Introduction (wie Anm. 10), 7-9; Kramer, Bezeichnungen für "Grenze“ (wie Anm. 93). 
military religious orders were such children of the frontier, and their important role for both settlement and military defence is discussed. Undoubtedly, such orders helped form very specific societies on the Iberian peninsular as well as in Eastern Central Europe; the sixth chapter analyzes the traits and heroes of such "frontier societies". In sum, the "thousand faces of the frontier" are so bewildering, that convincing definitions are in fact impossible to formulate. This finding is mirrored by medieval terminology, this paper's final subject: it too showed a wide variety, which serves to prove the point that even in medieval times borders and frontiers were perceived in many complex fashions. 